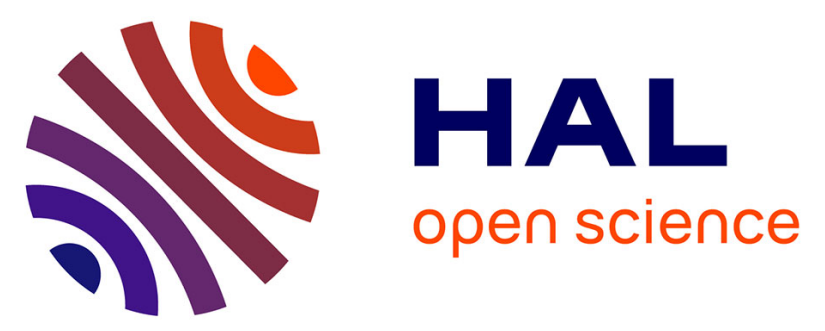

\title{
Quality Assessment of the First Measurements of Tropospheric Water Vapor and Temperature by the HAMSTRAD Radiometer Over Concordia Station, Antarctica
}

P. Ricaud, Fabien Carminati, Jean-Luc Attié, Yann Courcoux, Thomas Rose, C. Genthon, Andrea Pellegrini, Pascal Tremblin, Thomas August

\section{To cite this version:}

P. Ricaud, Fabien Carminati, Jean-Luc Attié, Yann Courcoux, Thomas Rose, et al.. Quality Assessment of the First Measurements of Tropospheric Water Vapor and Temperature by the HAMSTRAD Radiometer Over Concordia Station, Antarctica. IEEE Transactions on Geoscience and Remote Sensing, 2013, 51 (6), pp.3217-3239. 10.1109/TGRS.2012.2225627 . hal-00864744

\author{
HAL Id: hal-00864744 \\ https://hal.science/hal-00864744
}

Submitted on 10 Aug 2021

HAL is a multi-disciplinary open access archive for the deposit and dissemination of scientific research documents, whether they are published or not. The documents may come from teaching and research institutions in France or abroad, or from public or private research centers.
L'archive ouverte pluridisciplinaire HAL, est destinée au dépôt et à la diffusion de documents scientifiques de niveau recherche, publiés ou non, émanant des établissements d'enseignement et de recherche français ou étrangers, des laboratoires publics ou privés.

\section{(ㄷ)(i)}

Distributed under a Creative Commons Attribution| 4.0 International License 


\title{
Quality Assessment of the First Measurements of Tropospheric Water Vapor and Temperature by the HAMSTRAD Radiometer Over Concordia Station, Antarctica
}

\author{
Philippe Ricaud, Fabien Carminati, Jean-Luc Attié, Y. Courcoux, Thomas Rose, \\ Christophe Genthon, Andrea Pellegrini, Pascal Tremblin, and Thomas August
}

\begin{abstract}
The HAMSTRAD microwave instrument operates at 60 and $183 \mathrm{GHz}$ and measures temperature and water vapor, respectively, from 0 - to $10-\mathrm{km}$ altitude with a time resolution of $7 \mathrm{~min}$. The radiometer has been successfully deployed at Dome $\mathrm{C}$ (Concordia Station), Antarctica $\left(75^{\circ} 06^{\prime} \mathrm{S}, 123^{\circ} 21^{\prime} \mathrm{E}, 3233 \mathrm{~m}\right.$ amsl) during the first summertime campaign for 12 days in January-February 2009. The radiometer has been continuously running since January 2010, hosted within a dedicated shelter. We have used the very first set of HAMSTRAD data, recorded when the instrument was outdoors, to assess its potential to sound the troposphere over Dome $\mathbf{C}$, from the planetary boundary layer (PBL) up to the tropopause ( $\sim 6 \mathrm{~km}$ above surface, $\sim 9 \mathrm{~km}$ amsl). We have compared the HAMSTRAD measurements to several sets of measurements performed at the Dome-C station or in its vicinity: meteorological radiosondes, in situ PT100 and Humicap sondes along the vertical extent of a $45-\mathrm{m}$ tower, meteorological sensor attached to the HAMSTRAD instrument, and the spaceborne Infrared Atmospheric Sounding Interferometer (IASI) instrument onboard the EUMETSAT MetOp-A satellite in polar orbit. The variability of integrated water vapor (IWV) observed by HAMSTRAD with extremely low values of $0.5 \mathrm{~kg} \cdot \mathrm{m}^{-2}$ was also measured by the radiosondes (very high HAMSTRAD versus radiosonde correlation of 0.98 ), whereas IASI cloud-free measurements did not reproduce well the HAMSTRAD IWV vari-
\end{abstract}

P. Ricaud is with the Météo-France, GAME/CNRS, UMR 3589 Toulouse, France (e-mail: philippe.ricaud@meteo.fr).

F. Carminati is with the Météo-France, GAME/CNRS, UMR 3589 Toulouse, France, and also with the University of Maryland, College Park, MD 20742 USA.

J.-L. Attié is with the Météo-France, GAME/CNRS, UMR 3589 Toulouse, France, and also with the Laboratoire d'Aérologie, Toulouse University, 31400 Toulouse, France.

Y. Courcoux was with the Laboratoire de l'Atmosphère et des Cyclones, CNRS UMR, 8105 La Réunion, France. He is now with the Laboratoire Atmosphères, Milieux, Observations Spatiales, CNRS UMR 8190, Université Versailles Saint Quentin - Université Paris VI, 78280 Guyancourt, France.

T. Rose is with Radiometer Physics GmbH, 53340 Meckenheim, Germany.

C. Genthon is with the Laboratoire de Glaciologie et de Géophysique de l'Environnement, Grenoble, France.

A. Pellegrini is with the Energy and Sustainable Economic Development (ENEA), 00196 Roma, Italy.

P. Tremblin is with the Commissariat à l'Energie Atomique, Saclay, France.

T. August is with the European Organisation for the Exploitation of the Meteorological Satellites, Darmstadt, Germany. ation (weak HAMSTRAD versus IASI correlation of 0.58 ). The measurements of absolute humidity $\left(\mathrm{H}_{2} \mathrm{O}\right)$ from HAMSTRAD at Dome $\mathrm{C}$ cover a large vertical extent from the surface to about $6 \mathrm{~km}$ above surface with a high sensitivity in the free troposphere. The strong diurnal variation of $\mathrm{H}_{2} \mathrm{O}$ observed by the in situ sensors in the PBL is not well detected by the radiometer. In the free troposphere, the HAMSTRAD versus radiosonde $\mathrm{H}_{2} \mathrm{O}$ correlation can reach $0.8-0.9$. Around the tropopause, HAMSTRAD shows the same variability as IASI and radiosondes but with a dry bias of $0.01 \mathrm{~g} \cdot \mathrm{m}^{-3}$. HAMSTRAD tends to show a wetter atmosphere by $0.1-0.3 \mathrm{~g} \cdot \mathrm{m}^{-3}$ compared with radiosondes from the surface to $\sim 2-\mathrm{km}$ altitude and a drier atmosphere above by $\sim 0.1 \mathrm{~g} \cdot \mathrm{m}^{-3}$. The sensitivity of the temperature profiles from HAMSTRAD is very high in the PBL and in the free troposphere but degrades around the tropopause. The strong diurnal signal measured above the surface by HAMSTRAD (3-6 K) is consistent with all the other in situ data sets. The temporal evolution over the 12-day period in the PBL is also consistent with all other data sets (radiosondes, IASI, in situ sondes, and meteorological sensors). In the free troposphere and around the tropopause, the HAMSTRAD temporal evolution is consistent with that observed by radiosondes and IASI, although a cold bias exists compared with IASI and radiosondes around the tropopause. For heights less than $4 \mathrm{~km}$ above surface, HAMSTRAD correlates very well with radiosondes and in situ sensors (correlation better than 0.8 ) but less well with IASI (0.4). Below the tropopause, the IASI and HAMSTRAD correlation reaches 0.9 , whereas above the tropopause, the correlation of IASI and radiosondes with HAMSTRAD is rather low $(<0.5)$. Throughout the 12-day period (except on January 23), in the lowermost troposphere for heights less than $500 \mathrm{~m}$ above surface, the HAMSTRAD temperature profiles agree with the profiles measured by the radiosondes. From $500 \mathrm{~m}$ up to $5 \mathrm{~km}$ above the surface, the HAMSTRAD temperature profile has a cold bias from 1 to $5 \mathrm{~K}$ compared with the radiosondes, but for some dates (e.g., on January 25 and 29), the HAMSTRAD temperature is very close to the radiosonde temperature. HAMSTRAD generally measures a tropopause lower and warmer than the radiosondes except on some occasions, for instance, on January 23, 30, and 31. In the lower stratosphere, HAMSTRAD measurements of $\mathrm{H}_{2} \mathrm{O}$ and temperature have little sensitivity. Based upon 5-day back trajectory analyses, the great variability of $\mathrm{H}_{2} \mathrm{O}$ and temperature above Dome $\mathrm{C}$ as measured by the different instruments from the surface up to the tropopause over the 12-day period can be explained by the origin of air masses. The Dome-C site is found to be under the influence of the oceanic middle latitudes and the Antarctic coastal latitudes, but on some occasions, the air masses originated from the Antarctic continent are associated with colder and drier episodes.

Index Terms-Antarctica, atmospheric measurements, humidity measurements, least squares methods, microwave measurements, 
microwave radiometry, temperature measurements, time series analysis.

\section{INTRODUCTION}

$\mathbf{T}$ HE evolution of the polar regions is one of the main scientific issues in the context of global climate change. Various feedback mechanisms encountered at high latitudes result in sensitivity to global warming, and the responses of the temperature variations are faster than at the midlatitudes. The warming of the Antarctic winter troposphere is larger than anywhere else on Earth with a rate of 0.5 to $0.7 \mathrm{~K}$ per decade [1]. The poles differ by their surface geography and composition. While the North Pole is composed of sea ice and surrounded by numerous islands, there is a real continent under the Antarctic ice sheet. This configuration tends to slow down the Arctic meridional transport. The polar vortex is thus more intense and persistent in Antarctica, and the temperature is, as a consequence, colder than in the Arctic. The role of the Antarctic ice sheet is essential since it is an actor of temperature regulation through the extraction of the sensible heat flux from the atmosphere. During the austral winter, there is no solar radiation, and the surface is cooled by longwave surface emission within the very cold and dry atmosphere. During the austral summer, the absorption of solar shortwave radiation introduces a diurnal cycle and heats the surface, although heating is limited by the high albedo [2].

Water vapor $\left(\mathrm{H}_{2} \mathrm{O}\right)$ is the main greenhouse gas-emitting and gas-absorbing IR radiation. Changes in its abundance directly impact the radiative balance of the Earth, thus affecting climate evolution [3]. The Antarctic plateau (average altitude of $2500 \mathrm{~m}$ above sea level) is one of the coldest and driest places around the world. For these reasons, numerous atmospheric studies took place and are nowadays taking place, which are focused on: the evolution of climate (e.g., [4]), processes within the planetary boundary layer (PBL) (e.g., [5]-[7]), reactive species interacting with snowpack (e.g., [8] and [9]), and site seeing investigations for astronomical purposes (e.g., [10]-[12]).

The permanently manned Concordia Station is jointly operated by the French Institut polaire français Paul-Emile Victor and the Italian Programma Nazionale Ricerche in Antartide. Considering all the processes that play a key role in the evolution of temperature depending on the season, the Dome-C station is extremely interesting for studying the diurnal variations of temperature and humidity from summertime to wintertime, as presented in [13]. Indeed, the site is situated on the Antarctic Plateau at $3233 \mathrm{~m}$ amsl, with 24-h continuous daylight during summertime and no light during wintertime; climatological air surface temperature ranges between $-40{ }^{\circ} \mathrm{C}$ and $-20{ }^{\circ} \mathrm{C}$ in summertime and between $-80^{\circ} \mathrm{C}$ and $-60^{\circ} \mathrm{C}$ in wintertime [11]. Situated on the top of a large dome, there are no strong katabatic winds as they can be encountered at the coastal Dumont d'Urville station $\left(66^{\circ} \mathrm{S}, 140^{\circ} \mathrm{E}\right.$, sea level), since wind speed very unlikely exceeds $5 \mathrm{~m} \cdot \mathrm{s}^{-1}$ over the year. Interestingly, whatever the season considered, when temperature drops, humidity precipitates in the form of light ice crystals. Clouds are also very unlikely over the station and are mainly elevated cirrus clouds.
The $\mathrm{H}_{2} \mathrm{O}$ Antarctica Microwave Stratospheric and Tropospheric Radiometers (HAMSTRAD) program aims to develop two ground-based microwave radiometers to sound tropospheric and stratospheric water vapor $\left(\mathrm{H}_{2} \mathrm{O}\right)$ above Dome $\mathrm{C}$ (Concordia Station), Antarctica $\left(75^{\circ} 06^{\prime} \mathrm{S}, 123^{\circ} 21^{\prime} \mathrm{E}, 3233\right.$ $\mathrm{m}$ amsl) over a long time period. One radiometer has been deployed to date for the measurement of tropospheric $\mathrm{H}_{2} \mathrm{O}$ and temperature. The aim and the originality of the project are to detect the fingerprint of climate change onto the $\mathrm{H}_{2} \mathrm{O}$ and temperature trends over the Antarctic Plateau from the surface to the tropopause with a high time resolution (less than $1 \mathrm{~h}$ ) and to provide these data to Numerical Weather Prediction and Climate centers for improving their analyses and forecasts. We will show that the instrument is able to sound the lowermost troposphere to study processes in the PBL [14]. The great majority of ground-based microwave radiometers dedicated to sound tropospheric $\mathrm{H}_{2} \mathrm{O}$ uses the $6_{16}-5_{23}$ transition line at $22.235 \mathrm{GHz}$ (e.g., [15]) and not the $3_{13}-2_{20}$ transition line at $183.310 \mathrm{GHz}$ (e.g., [16] and [17]) because this latter line has little or no sensitivity to tropospheric water vapor for ground observations outside of the cold and dry Arctic/Antarctic zones since it saturates for a small cloud water path. The 22-GHz line does not saturate in the majority of sites around the world but, because of its weak intensity, has little or no sensitivity to tropospheric $\mathrm{H}_{2} \mathrm{O}$ in extremely cold and dry conditions as the ones encountered at high latitudes and particularly over the Antarctic plateau. The best candidate to detect tropospheric $\mathrm{H}_{2} \mathrm{O}$ in these extreme environments is thus the $183-\mathrm{GHz}$ line. Radiometers operating at this frequency have been successfully deployed in the Arctic as, for instance, during the Arctic Winter Experiment held at the Atmospheric Radiation Measurement Program's North Slope of Alaska site near Barrow (AK, USA) [18] with the ground-based scanning radiometer [19] measuring, among other transitions, the $183-\mathrm{GHz} \mathrm{H}_{2} \mathrm{O}$ line. In these dry Arctic conditions, precipitable water vapor ranging from $1-2 \mathrm{~mm}$ can be estimated to within 5\% uncertainty [20]. We thus developed and installed an automated instrument for continuous operation in even more extreme conditions, for precipitable water vapor much less than $1 \mathrm{~mm}$ and surface temperatures less than $-70^{\circ} \mathrm{C}$ [11].

The HAMSTRAD-Tropo (hereafter named HAMSTRAD) radiometer has been already presented in [21]. To summarize, it is a state-of-the-art microwave radiometer dedicated to the measurement of tropospheric $\mathrm{H}_{2} \mathrm{O}$ at $169-197 \mathrm{GHz}$ (G-band, strong water vapor line at $183.3 \mathrm{GHz}$ ), together with tropospheric temperature from the oxygen $\left(\mathrm{O}_{2}\right)$ line $(51-59 \mathrm{GHz}$, V-band, lower frequency wing of the $\mathrm{O}_{2}$ line), in very cold and dry environments, such as the ones encountered at Dome $\mathrm{C}$ all over the year. From these emission lines, absolute humidity and temperature vertical profiles can be retrieved from $0-\mathrm{km}$ to about $10-\mathrm{km}$ altitude with a temporal resolution of $7 \mathrm{~min}$, although the instrument loses sensitivity at an altitude of about $6 \mathrm{~km}$ above the site where the instrument is located.

HAMSTRAD was first deployed at the Pic du Midi station $\left(42^{\circ} 56^{\prime} \mathrm{N}, 0^{\circ} 08^{\prime} \mathrm{E}, 2877 \mathrm{~m}\right.$ amsl, France) from February to June 2008. A comprehensive assessment exercise was performed regarding $\mathrm{H}_{2} \mathrm{O}$ measurements as compared with radiosondes and the spaceborne instrument Infrared Atmospheric Sounding Interferometer (IASI), together with the outputs from 
TABLE I

VERTICAL RESOLUTION AND $1-\sigma$ RMS RANDOM ERROR ASSOCIATED TO THE WATER VAPOR MEASUREMENTS WiTHIN DifFERENT LAYERS OF THE ATMOsphere [Planetary Boundary LAYER (PBL), FreE Troposphere (FT), AND UPPER Troposphere/Lower Stratosphere (UTLS)], ESTIMATED FOR HAMSTRAD, RADIOSONDES, IN SITU SENSORS, AND IASI, RESPECTIVELY

\begin{tabular}{|c|c|c|c|c|c|c|}
\hline & \multicolumn{3}{|c|}{ Vertical resolutions } & \multicolumn{3}{c|}{ Errors } \\
\cline { 2 - 7 } & PBL & FT & UTLS & PBL & FT & UTLS \\
\hline HAMSTRAD $^{1}$ & $30-50 \mathrm{~m}$ & $100 \mathrm{~m}$ & $500 \mathrm{~m}$ & $\begin{array}{c}0.05 \mathrm{~g} \mathrm{~m}^{-3} \\
(10 \%)\end{array}$ & $\begin{array}{c}0.03 \mathrm{~g} \mathrm{~m}^{-3} \\
(10-15 \%)\end{array}$ & $\begin{array}{c}0.005 \mathrm{~g} \mathrm{~m}^{-3} \\
(15 \%)\end{array}$ \\
\hline Radiosondes $^{2}$ & $18 \mathrm{~m}$ & $6 \mathrm{~m}$ & $5 \mathrm{~m}$ & $5 \%$ & $5 \%$ & $5 \%$ \\
\hline In-situ LGGE sensors & - & - & - & $3 \%$ & - & - \\
\hline $\begin{array}{c}\text { In-situ HAMSTRAD } \\
\text { meteorological sensor }\end{array}$ & - & - & - & $3 \%$ & - & - \\
\hline IASI & $1000 \mathrm{~m}$ & $1500 \mathrm{~m}$ & $2000 \mathrm{~m}$ & $<10 \%$ & $<10 \%$ & $<10 \%$ \\
\hline
\end{tabular}

${ }^{\mathrm{I}}$ Random error associated with a 7 -minute integration time (see [21])

${ }^{2}$ Vertical resolution estimated from yearly-averaged data representative of the year 2010 at Dome C.

the nonhydrostatic mesoscale atmospheric model (MESO-NH). In the very dry conditions such as the ones encountered in February 2008, the radiometer behaved consistently with the other data sets, whereas in standard and wet conditions such as the ones encountered in March-June 2008, a wet bias in comparison to the radiosondes and IASI was detected in the lower troposphere [22].

After this successful validation campaign in Europe, the HAMSTRAD radiometer was sent and deployed at Dome C in January 2009. Since the shelter that ought to house the radiometer was not fully equipped, we installed the instrument outdoors (mean outdoor surface temperature of $-35{ }^{\circ} \mathrm{C}$ ) and performed measurements of water vapor and temperature over a limited period of 12 days from January 22 to February 2, 2009. After that date, we forced the instrument to stop operation and stored it at room temperature $\left(-20{ }^{\circ} \mathrm{C}\right)$ during the winterover period. In January 2010, the HAMSTRAD radiometer has been deployed inside a fully equipped shelter at Dome $\mathrm{C}$ and has been in automated operation since then. A comprehensive validation exercise is currently being performed regarding the 2010 measurements, and genuine scientific results have been already highlighted regarding short-term (diurnal variation) and midterm (seasonal variation) variability of $\mathrm{H}_{2} \mathrm{O}$ and temperature in the PBL [13], [14]. The scientific outcomes from the measurements performed by a series of instruments including HAMSTRAD during the whole year 2010 are presented in [23] and [24]. The HAMSTRAD measurements from the 2009 campaign have been already useful for scientific studies (e.g., [25]) and helped to characterize the quality of integrated water vapor (IWV) observations at Dome C.

This paper deals with the first measurements of $\mathrm{H}_{2} \mathrm{O}$ and temperature measured by HAMSTRAD at Dome $\mathrm{C}$ from January 22 to February 2, 2009. In order to assess the quality of these measurements, we compared the HAMSTRAD data sets with coincident measurements of $\mathrm{H}_{2} \mathrm{O}$ and temperature performed by several instruments launched from Dome $\mathrm{C}$ (meteorological radiosondes), deployed at Dome C (PT100 and Humicap in situ sensors) along the vertical extent of a 45-m tower, and orbiting above Dome C (the spaceborne IASI instrument). This paper is structured as follows: In Section II, we present the data sets used in our analysis. In Section III, we show the measurements of IWV and $\mathrm{H}_{2} \mathrm{O}$ profiles from HAMSTRAD and assess their quality as compared with all the other data sets in terms of temporal evolution and statistical analysis (mean, standard deviation, bias, and correlation). Section IV deals with the measurements of temperature performed by HAMSTRAD and, as for $\mathrm{H}_{2} \mathrm{O}$, comparisons to the other data sets in terms of temporal evolution and statistical analysis. The conclusions of the study are presented in Section V, and an Appendix dealing with the vertical resolution of the measurements finalizes this paper.

\section{MEASURED DATA SETS}

\section{A. HAMSTRAD}

The HAMSTRAD radiometer is presented in [21]. It uses spectral information in the frequency ranges 51-59 GHz (oxygen line) and 169-197 GHz (water vapor line) to derive accurate tropospheric profiles of temperature (accuracy range $0.25-1.0 \mathrm{~K}$ ) and absolute humidity (accuracy range 0.005$0.05 \mathrm{~g} \cdot \mathrm{m}^{-3}$ ), respectively, together with IWV (accuracy of about $0.05 \mathrm{~kg} \cdot \mathrm{m}^{-2}$ or $5 \%$ ) and liquid water path (LWP). Due to the extremely dry conditions encountered at Dome C, the LWP retrievals were not developed for this particular site, in contrast to what has been done at Pic du Midi. Tables I and II summarize the vertical resolutions and the $1-\sigma$ root-mean-square (RMS) errors associated to the measurements of $\mathrm{H}_{2} \mathrm{O}$ and temperature, respectively, for the different instruments used in our analysis in the PBL, the free troposphere, and the upper troposphere/lower stratosphere. For HAMSTRAD, based on theoretical studies elaborated during the instrument development [21], on two methods presented in the Appendix using 2009 data at Dome C and on studies focused on the PBL from measurements performed at Dome $\mathrm{C}$ in 2010 [14], the vertical resolution of $\mathrm{H}_{2} \mathrm{O}$ and temperature measurements is $30-50 \mathrm{~m}$ and $20-50 \mathrm{~m}$ in the $\mathrm{PBL}$, respectively; $100 \mathrm{~m}$ in the free troposphere; and $500 \mathrm{~m}$ in the upper troposphere/lower stratosphere for both $\mathrm{H}_{2} \mathrm{O}$ and temperature measurements. For HAMSTRAD, errors in absolute humidity $\left(\mathrm{g} \cdot \mathrm{m}^{-3}\right)$ listed in Table I are decreasing with altitude as the vertical profile but are increasing in relative unit from about $10 \%$ in the PBL to about $15 \%$ in the upper troposphere/lower stratosphere (UTLS).

HAMSTRAD has two observation modes dedicated to temperature profile retrievals: 1) boundary layer mode, where the instrument is scanning the atmosphere at low elevations $\left(5^{\circ}-45^{\circ}\right)$ to obtain accurate temperature profiles from the surface to $2-3-\mathrm{km}$ altitude, and 2) full troposphere mode, where the instrument is scanning the atmosphere at higher elevations 
TABLE II

VERTICAL RESOlUtion AND $1-\sigma$ RMS RANDOM ERROR ASSOCIATED TO THE TEMPERATURE MEASUREMENTS Within DifFERENT LAYERS OF THE AtMosphere [Planetary Boundary LAYER (PBL), Free Troposphere (FT), AND UPPER Troposphere/LOWER STRATOSPHERE (UTLS)], ESTIMATED FOR HAMSTRAD, RADIOSONDES, IN $S I T U$ SENSORS, AND IASI, RESPECTIVELY

\begin{tabular}{|c|c|c|c|c|c|c|}
\hline & \multicolumn{3}{|c|}{ Vertical resolutions } & \multicolumn{3}{c|}{ Errors } \\
\cline { 2 - 7 } & PBL & FT & UTLS & PBL & FT & UTLS \\
\hline HAMSTRAD $^{1}$ & $20-50 \mathrm{~m}$ & $100 \mathrm{~m}$ & $500 \mathrm{~m}$ & $0.25 \mathrm{~K}$ & $0.5 \mathrm{~K}$ & $1 \mathrm{~K}$ \\
\hline Radiosondes $^{2}$ & $18 \mathrm{~m}$ & $6 \mathrm{~m}$ & $5 \mathrm{~m}$ & $0.5 \mathrm{~K}$ & $0.5 \mathrm{~K}$ & $0.5 \mathrm{~K}$ \\
\hline In-situ LGGE sensor & - & - & - & $0.15 \mathrm{~K}$ & - & - \\
\hline In-situ CEA sensor & - & - & - & $0.15 \mathrm{~K}$ & - & - \\
\hline $\begin{array}{c}\text { In-situ HAMSTRAD } \\
\text { meteorological sensor }\end{array}$ & - & - & - & $0.15 \mathrm{~K}$ & - & - \\
\hline IASI & $1000 \mathrm{~m}$ & $1500 \mathrm{~m}$ & $2000 \mathrm{~m}$ & $<1 \mathrm{~K}$ & $<1 \mathrm{~K}$ & $<1 \mathrm{~K}$ \\
\hline
\end{tabular}

${ }^{1}$ Random error associated to a 7-minute integration time (see [21])

${ }^{2}$ Vertical resolution estimated from yearly-averaged data representative of the year 2010 at Dome C

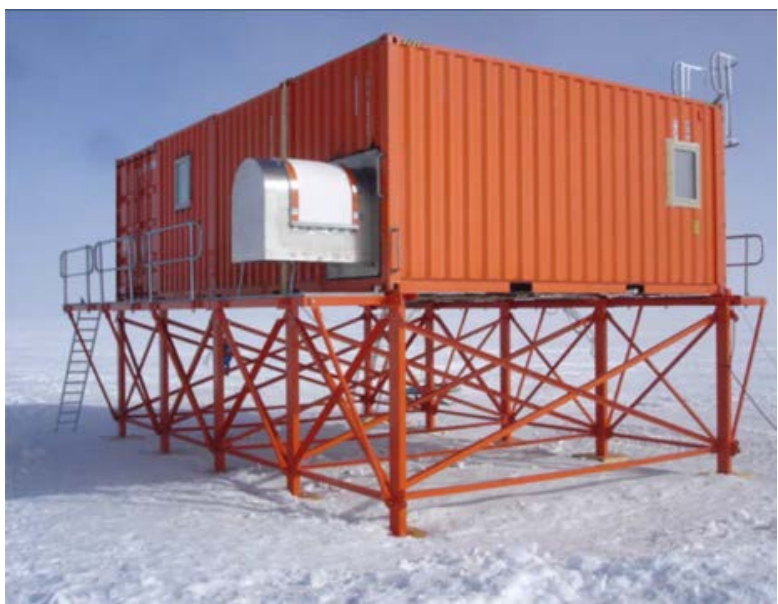

Fig. 1. (Orange) Shelter and (white material) the shield protecting HAMSTRAD for nominal operation since January 2010.

$\left(45^{\circ}-90^{\circ}\right)$ to obtain accurate temperature profiles from $2-3-\mathrm{km}$ to $\sim 10-\mathrm{km}$ altitude. Composite temperature profiles can then be calculated by combining the two modes of observation. $\mathrm{H}_{2} \mathrm{O}$ is retrieved using only one mode of observation from low elevations to zenith. The retrieval vertical grid is set to 39 levels, namely, at $0,10,30,50,75,100,125,150,200,250,325,400$, $475,550,625,700,800,900,1000,1150,1300,1450,1600$, $1800,2000,2200,2500,2800,3100,3500,3900,4400,5000$, $5600,6200,7000,8000,9000$, and $10000 \mathrm{~m}$.

Since the Dome-C outdoor temperature ranges from about $-30{ }^{\circ} \mathrm{C}$ in summer to $-80{ }^{\circ} \mathrm{C}$ in winter, it was decided to install a heated shelter (see Fig. 1), including a shield to protect the instrument to make sure nominal operating conditions are maintained. The shield is composed of a rigid frame covered by a Plastazote LD24 plate, a low-density polyethylene foam, namely, a lossy material that is $95 \%$ transparent to microwave radiation below $200 \mathrm{GHz}$. It is basically the same material used to protect the observational window of the HAMSTRAD radiometer.

Unfortunately, the shelter was not fully equipped in January 2009 (electrical power, insulation, etc.). We thus decided to install the HAMSTRAD radiometer outside (see Fig. 2) with outdoor temperatures ranging from $-30{ }^{\circ} \mathrm{C}$ to $-40{ }^{\circ} \mathrm{C}$. The instrument was operated over 12 days from January 22 to February 2, 2009. At the end of that period, we stopped the operation.

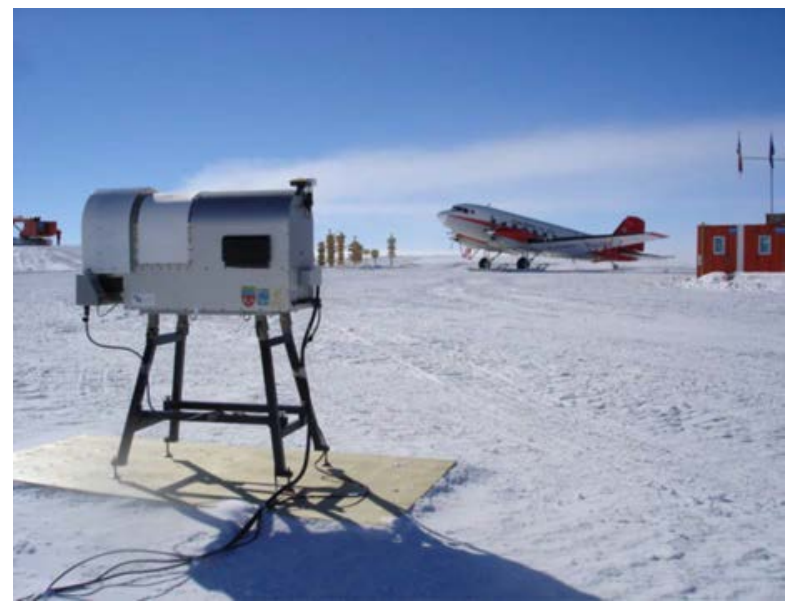

Fig. 2. HAMSTRAD instrument installed outdoors in January-February 2009 in the vicinity of the summer camp at Dome C, Concordia Station, Antarctica.

In order to calibrate spectra, we brought a liquid nitrogen plant from Europe to produce liquid nitrogen at Dome C. Unfortunately, due to microlosses in the device probably induced by the very low temperature and the very low pressure of operation (typically $\sim 650 \mathrm{hPa}$ ), we did not succeed in producing liquid nitrogen to establish a cold load in order to perform calibration of measured brightness temperatures. We thus used the calibration files produced when the instrument was operated at Pic du Midi during the period February-June 2008. From January 22 to 26, 2009 at 04:00 UTC, we have inadvertently used a blue foam attached to the observation window of the radiometer. This foam is usually used with microwave radiometers operating at 22 and $60 \mathrm{GHz}$ to detect $\mathrm{H}_{2} \mathrm{O}$ and $\mathrm{O}_{2}$ lines, respectively. After January 26 at 04:00 UTC, we used the standard (white) LD24 plate. The blue and white foams are indistinctly used for the measurements of temperature at $60 \mathrm{GHz}$ and are selected for the measurements of $\mathrm{H}_{2} \mathrm{O}$ at 22 and $183 \mathrm{GHz}$, respectively. Indeed, for the same depth, the opacity of the blue and white foams slightly differs at 22 and $183 \mathrm{GHz}$ but is similar at $60 \mathrm{GHz}$. Since the last liquid nitrogen calibration was performed at the Pic du Midi with a white foam, the use of a blue foam at Dome $\mathrm{C}$ has impacted the retrievals of absolute humidity by a systematic factor of $+5 \%$ to $+20 \%$ in the PBL and in the lower troposphere. This will be detailed in Section III. Note that an in situ meteorological sensor is also attached to the instrument and can provide surface pressure, temperature, and 


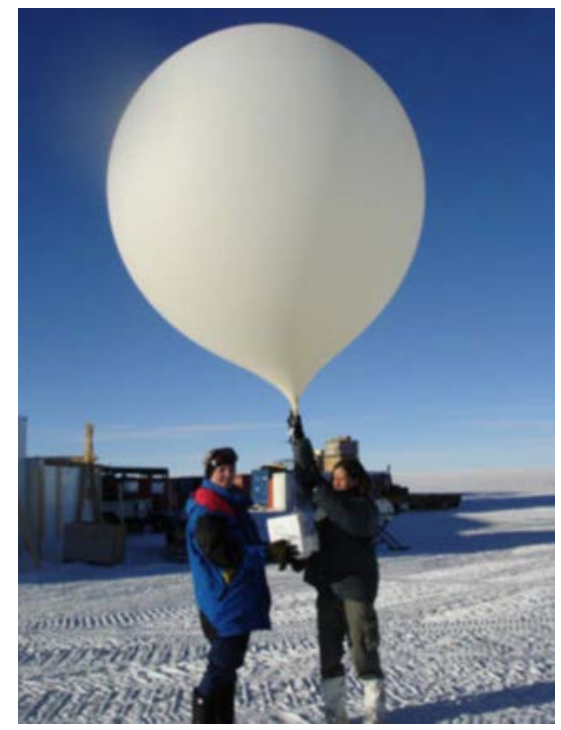

Fig. 3. Launch of a meteorological radiosonde including an ozonesonde by two operators in January 2009 at Dome C, Concordia Station, Antarctica.

humidity. This information is not used in the analysis (retrieval) of the HAMSTRAD measurements and, consequently, will be used for assessing the HAMSTRAD retrievals at the surface.

When statistically comparing with coincident IASI measurements, the HAMSTRAD profiles were selected within a 1-h window centered at the time of the IASI overpass within a $2^{\circ} \times 2^{\circ}$ latitude-longitude bin centered at the Dome-C location. When statistically comparing with coincident sonde measurements, the HAMSTRAD profiles were selected within a 1-h window centered at 12:00 UTC.

\section{B. Radiosondes}

The radiosonde equipment is a DIGICORA III MW31, manufactured by Vaisala [26]. Regular radiosondes started during the first overwintering at Concordia Station on March 23, 2005. During winter 2005, due to technical constraints on the helium supplies, only three launches per week were possible. However, due to the cooperative launch of radiosondes made by the astronomy community, a reasonable number of about 18 profiles per month were produced. Since spring 2005, one radiosonde per day has been scheduled at 12:00 UTC, namely, 20:00 local solar time. Profiles are inserted into the Global Telecommunication System of the World Meteorological Organization. After validation, data are also made available to the scientific community through a web interface at www. climantartide.it.

In 2009, we used Vaisala radiosondes RS-92SPGW (see Fig. 3) that measure air temperature, pressure, relative humidity, and wind. In particular, RS92 radiosondes make use of twin heated humidity sensors that decrease the dry bias detected in previous models of radiosondes ([27] and [28]). In our analysis, we present two sets of vertical profiles of $\mathrm{H}_{2} \mathrm{O}$ from radiosondes. First, we refer to "radiosondes" when the standard Vaisala evaluation routines are used to retrieve $\mathrm{H}_{2} \mathrm{O}$ and temperature profiles with no correction of time lag nor sensor heating effects. It is unfortunately well known that these profiles show

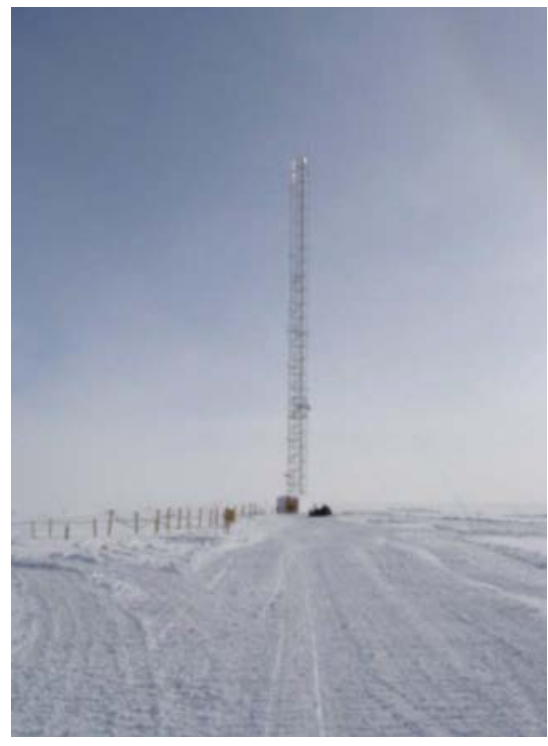

Fig. 4. Tower (45-m high) supporting the PT100 sondes at Dome C, Concordia Station, Antarctica.

systematic dry biases, from $5 \%$ at the surface up to $40 \%-50 \%$ in the upper troposphere/lower stratosphere during daytime [29]. Second, to cope with this recurrent problem, we apply a correction method to the humidity profiles as detailed in [30] and applied in [25], and we refer to these corrected $\mathrm{H}_{2} \mathrm{O}$ profiles as "corrected radiosondes."

\section{In-Situ Sondes}

During the 2009 measurement period, two groups have installed in situ PT100 and Humicap sondes along the vertical extent of a 45-m tower (see Fig. 4) for measuring temperature and humidity, respectively: the Laboratoire de Glaciologie et de Géophysique de l'Environnement, Grenoble, France (hereafter LGGE) and the Commissariat à l'Energie Atomique, Saclay, France (hereafter CEA). Basically, six levels of measurements were available at 4.6-, 12-, 19.4-, 26.9-, 34.2-, and 43.4-m altitude. LGGE provided both temperature and $\mathrm{H}_{2} \mathrm{O}$ fields, whereas for CEA, only temperature fields were actually available over the period January 22-February 2, 2009. These data were linearly interpolated and extrapolated onto the HAMSTRAD retrieval grid at $0,10,30$, and $50 \mathrm{~m}$ above surface.

For LGGE, details of the sensor setting and of the sensor installation along the vertical extent of a 45-m tower are available in [31]. However, unlike in [31], where Vaisala/Campbell HMP45c thermo-hygrometers were used in passively ventilated shields, the data here are from PT100 DIN IEC 751 class 1/10 thermistors. The thermistor accuracy is better than $\pm 0.15{ }^{\circ} \mathrm{C}$ at the typical temperatures encountered during the experiment, although biases due to radiation contamination may be an issue. To prevent such biases, the PT100 sensors were not only shielded but also force ventilated using Young 43502 shields. The sensors were interrogated at 10-s intervals, then averaged on a half-hour time step. The half-hourly data are reported and used in the present study. For CEA, the same kind of sensors was used but not force ventilated and shielded (see [12]). 
For LGGE, atmospheric moisture is measured by Humicap capacitive hydroactive sensors produced by Vaisala. Humicap is a built-in part of the RS92 radiosondes launched at Dome C. They are also used in the Vaisala HMP45ac and HMP155 thermo-hygrometers deployed on the tower [31]. The accuracy is better than $\pm 3 \%$ relative humidity at temperatures about $-40{ }^{\circ} \mathrm{C}$ for values close to saturation.

\section{IASI}

The MetOp-A EUMETSAT satellite was launched on October 19, 2006. It carries a set of eight instruments, including the IASI, that potentially offers remote sensing capabilities for both meteorology and climatology. MetOp-A flies in a sunsynchronous polar orbit at a mean altitude of $\sim 815 \mathrm{~km}$. The orbit is inclined $98.7^{\circ}$ to the equator and crosses the equator (descending node) at 09:30 local solar time. The time for one orbit is $101 \mathrm{~min}$.

The IASI instrument (see, e.g., http://smsc.cnes.fr/IASI) is a high-resolution infrared sounder that was designed for the measurement of temperature profiles with an accuracy of better than $1 \mathrm{~K}$ in the troposphere and lower stratosphere and humidity profiles with an accuracy of better than $10 \%$ in the troposphere and lower stratosphere [32], [33]. IASI is an accurately calibrated Fourier transform spectrometer whose design is based on a classical Michelson interferometer. It covers the spectral range from $3.6 \mu \mathrm{m}\left(2760 \mathrm{~cm}^{-1}\right)$ to $15.5 \mu \mathrm{m}$ $\left(645 \mathrm{~cm}^{-1}\right)$ with a spectral resolution between 0.35 and $0.5 \mathrm{~cm}^{-1}$. To achieve global coverage, the IASI instrument observes the Earth with a cross-track swath angle of $\pm 48.3^{\circ}$. The instrument field of view consists of four circular pixels of $0.8^{\circ}$ angular diameter, which corresponds to $12 \mathrm{~km}$ on the Earth at nadir. The vertical resolution is $1 \mathrm{~km}, 1.5 \mathrm{~km}$, and $2 \mathrm{~km}$ in the PBL, free troposphere, and upper troposphere/lower stratosphere, respectively [32], [33], for both temperature and $\mathrm{H}_{2} \mathrm{O}$ (see Tables I and II).

We are using the operational level 2 (L2) data (geophysical data) provided by EUMETSAT that produces near realtime (NRT) vertical profiles of $\mathrm{H}_{2} \mathrm{O}$ and temperature on a fixed vertical pressure grid from 1000 to $0.1 \mathrm{hPa}$ with an accuracy of $10 \%$ and $1 \mathrm{~K}$, respectively [34]. For the methods used to retrieve the vertical profiles of $\mathrm{H}_{2} \mathrm{O}$ and temperature, the reader should refer to [34] and [35]. The $\mathrm{H}_{2} \mathrm{O}$ and temperature vertical profiles provided by EUMETSAT for the period covering January-February 2009 have been selected within a $2^{\circ} \times 2^{\circ}$ bin centered at the location of the Dome-C station. Because the IASI instrument provides soundings from a cross-track scan with a $2200-\mathrm{km}$-wide swath, the actual number of IASI profiles available in the $2^{\circ} \times 2^{\circ}$ bin is variable.

Furthermore, we have only considered IASI measurements without any cloud contamination in the line of sight. This explains why IASI measurements may not be available for some days. Time associated to cloud-free measurements selected above the Dome-C station ranges from 13:00 to 02:00 UTC but is mainly concentrated within two time intervals: 16:00-19:00 and 23:00-02:00 UTC. The IASI $\mathrm{H}_{2} \mathrm{O}$ mass mixing ratio $\left(\mathrm{kg} \cdot \mathrm{kg}^{-1}\right)$ provided by EUMETSAT has been converted into

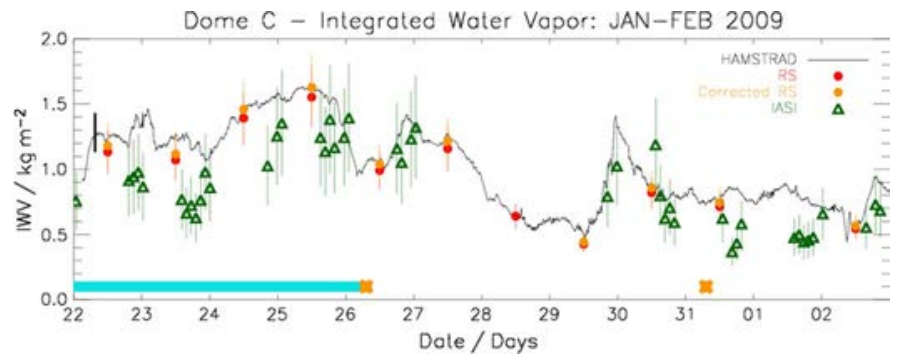

Fig. 5. Temporal evolution of IWV as measured by (black line) HAMSTRAD, (red filled circles) the radiosondes, (orange filled circles) the corrected radiosondes, and by (green thick triangles) IASI above Dome C from January 22 to February 2, 2009. The vertical error bars associated to each data set represent the $3-\sigma$ error, except that, for HAMSTRAD and for the sake of clarity, only one vertical bar is represented on (thick line) January 22, 2009. The light blue horizontal bar represents the period from January 22 to January 26 at 04:00 UTC when a blue foam was attached to the HAMSTRAD observation window. The two orange crosses represent the dates when a major reboot has been performed.

absolute humidity $\left(\mathrm{g} \cdot \mathrm{m}^{-3}\right)$. The IASI vertical scale has been transformed from the original pressure grid into an altitude grid by considering the hydrostatic equilibrium equation and the surface pressure and temperature regularly measured at Dome C by the HAMSTRAD in situ meteorological sensors.

\section{WATER VAPOR}

\section{A. IWV}

First of all, we present in Fig. 5 the temporal evolution of IWV, the water vapor integrated along the vertical from the measured vertical profiles, above the Dome-C site as measured by the three sensors: HAMSTRAD, radiosondes, and IASI. After a period where IWV increases from $\sim 1$ to $\sim 1.6 \mathrm{~kg} \cdot \mathrm{m}^{-2}$ (January 22-25, 2009), HAMSTRAD detects a rapid decrease to $0.5 \mathrm{~kg} \cdot \mathrm{m}^{-2}$ by 12:00 UTC on January 29,2009 , then a rapid increase up to $1.4 \mathrm{~kg} \cdot \mathrm{m}^{-2}$ in less than $12 \mathrm{~h}$ and a slow decrease to the end of the period on February 2, 2009. Being given that the $1-\sigma$ error for HAMSTRAD IWV is $\sim 0.05 \mathrm{~kg} \cdot \mathrm{m}^{-2}$, the measured extreme variability $\left(\sim 1 \mathrm{~kg} \cdot \mathrm{m}^{-2}\right)$ within few hours is not unusual at Dome $\mathrm{C}$ despite the fact that the site is far from the coast (about $1100 \mathrm{~km}$ away) and thus weakly affected by oceanic constraints. Although the period corresponds to summertime, the amount of water is extremely low $\left(\leq 1.6 \mathrm{~kg} \cdot \mathrm{m}^{-2}\right)$, values consistent with the IWVs observed in previous summer periods at Dome C [11] and at the Pic du Midi in the extremely dry situation of February 2008 [21].

The time evolution of IWV calculated from radiosondes is consistent with HAMSTRAD measurements, with a slightly lower amount. The peak in IWV measured by HAMSTRAD on January 30 at 00:00 UTC is naturally not observed by the radiosondes because of the regular sampling performed at 12:00 UTC. The linear Pearson correlation coefficient between HAMSTRAD and radiosondes is very high (0.98) with a slight dry bias of radiosondes versus HAMSTRAD of $0.07 \mathrm{~kg} \cdot \mathrm{m}^{-2}$ $(11 \%)$. If we now consider the corrected radiosondes, it is obvious that they follow even better the HAMSTRAD evolution of IWV, with the same correlation but a bias reduced to $0.03 \mathrm{~kg}$. $\mathrm{m}^{-2}(4 \%)$. This is consistent with the comparisons performed in [25] using corrected RS92 sondes and HAMSTRAD over 
the same period (only 10 corrected radiosondes are available out of 11 over the 12-day period), although the bias is greater: $-0.26 \pm 0.19 \mathrm{~kg} \cdot \mathrm{m}^{-2}$. Comparisons with other data sets (in situ, spaceborne, analyses, etc.) in 2010 [12] tend to show that IWV from HAMSTRAD is not biased by more than 5\%. This means that the calibration of the HAMSTRAD microwave radiometer is correctly performed when using the appropriate foam. However, when considering HAMSTRAD tropospheric $\mathrm{H}_{2} \mathrm{O}$ profiles, we have observed that the wet bias in the PBL was not extending throughout the troposphere, and a significant dry bias was detected at high altitudes to offset it (see next section).

Considering now IWV calculated from cloud-free IASI measurements, the agreement is less good. The general shape of the temporal variation is well depicted by the IASI measurements, including the net increase from January 29 at 12:00 UTC to January 30 at 00:00 UTC, but a nonnegligible dry bias is present throughout the entire period, except on January 30 around 00:00 UTC. Indeed, the correlation between HAMSTRAD and IASI is rather weak (0.58) with a strong dry bias of IASI versus HAMSTRAD of $0.14 \mathrm{~kg} \cdot \mathrm{m}^{-2}(19 \%)$. This general feature was also observed in 2010 [13], [14]. This is probably due to 1) the influence of the surface emission parameter over Antarctica that is currently being revisited in the official IASI retrieval scheme and 2) the impact of the vertical resolution of IASI $(\sim 1 \mathrm{~km})$ in the lower troposphere that tends to smear out the vertical gradient in $\mathrm{H}_{2} \mathrm{O}$ and lessens the absolute humidity (see Appendix and Section III-C).

We have already noticed that IWV tends to significantly decrease on January 27-29 and increase within $12 \mathrm{~h}$ by the end of January 29 until the beginning of January 30 considering all the data sets. To investigate the origin of this extreme variability in IWV, we have considered (see Fig. 6) a 5-day back trajectory study based upon the European Centre for MediumRange Weather Forecasts (ECMWF) analyses starting from the Dome-C location at six different pressure levels from the PBL $(600 \mathrm{hPa})$ to the free troposphere $(500,400$, and $300 \mathrm{hPa})$ up to the upper troposphere/lower stratosphere (200 and $100 \mathrm{hPa}$ ). In January-February 2009, considering the ECMWF analyses (not shown), the $\mathrm{H}_{2} \mathrm{O}$ field from 600 to $100 \mathrm{hPa}$ shows a drier atmosphere over the Antarctic continent than over the midlatitudes and a temperature field colder over the Antarctic continent than over the midlatitudes from 600 to $300 \mathrm{hPa}$, and conversely, from 200 to $100 \mathrm{hPa}$.

During the first half of the 12-day period, namely, from January 22 to 27 , at all pressure levels from 400 to $100 \mathrm{hPa}$, the air masses are essentially coming from the middle latitudes $\left(45^{\circ} \mathrm{S}-60^{\circ} \mathrm{S}\right)$, where $\mathrm{H}_{2} \mathrm{O}$ amounts are greater than at high southern latitudes, except at $600 \mathrm{hPa}$ where the air masses are originating from the Antarctic Plateau. Note that the surface pressure at Dome C is about $650 \mathrm{hPa}$. On January 28, the air masses are coming from the coast of the Eastern Antarctic plateau (in the sector $60^{\circ} \mathrm{S}-65^{\circ} \mathrm{S}$ and $90^{\circ} \mathrm{E}-150^{\circ} \mathrm{E}$ ) and thus are associated to drier air than during the previous days. On January 29, all the air masses have sampled an atmosphere above the Antarctic continent, and for the highest pressures (lowest altitudes) passed in the vicinity of the South Pole, imprint of the observed very dry episode at Dome C. After January 30 , the 5-day back trajectories are essentially origi- nating from midlatitudes southward of South Africa, whatever the levels considered, thus bringing water-vapor-enriched air masses over Dome C.

\section{B. Vertical Profiles}

The vertical profiles of $\mathrm{H}_{2} \mathrm{O}$ as measured by HAMSTRAD from January 22 to February 2, 2009 in temporal coincidence with the radiosondes launched at 12:00 UTC above the Dome-C site are shown in Fig. 7. Note that no radiosonde launch was performed on February 1, 2009. Despite the fact that the IWVs from HAMSTRAD are in very good agreement with the measurements from the sondes, the vertical distribution of $\mathrm{H}_{2} \mathrm{O}$ from HAMSTRAD tends to show a systematic deviation relative to the sondes, namely, a wet bias of $\sim 0.5 \mathrm{~g} \cdot \mathrm{m}^{-3}$ in the PBL (roughly a factor $3-5$ ), $0.1-0.3 \mathrm{~g} \cdot \mathrm{m}^{-3}$ in the troposphere, and a dry bias of $\sim 0.1 \mathrm{~g} \cdot \mathrm{m}^{-3}$ in the upper troposphere over the entire period. On January 26 and 31, this systematic effect is similar but slightly weaker in amplitude. Note that the difference between radiosondes and corrected radiosondes is negligible along the vertical. The domain where the measurements from HAMSTRAD and the sondes coincide is always located in the range $1.5-2.5 \mathrm{~km}$ above the Dome-C site, except again on January 26 and 31 . Note that such a systematic bias along the vertical was not present when the instrument was installed at Pic du Midi, particularly in February 2008 when the amounts of $\mathrm{H}_{2} \mathrm{O}$ were comparable to those encountered at Dome C in January-February 2009. As pointed out in the previous section, IWV as measured by HAMSTRAD is consistent with IWV from radiosondes. Thus, the wet bias observed in the lowermost troposphere does not extend throughout the atmosphere, and a significant dry bias is detected at high altitude to offset it.

In order to explain such a systematic behavior observed in 2009 and 2010 [14], [23], [24], we must note that the presently used regression method was initially developed for analyzing the HAMSTRAD spectra from radiosonde profiles launched at the South Pole and the McMurdo stations in Antarctica. A new linear regression retrieval method based upon a set of four years of radiosondes launched at Dome C prior to January 2009 has been recently developed. However, preliminary results from a subset of 2009 measurements (not shown) do not exhibit a significant impact in the vertical structure of the $\mathrm{H}_{2} \mathrm{O}$ profiles except a slightly drier lowermost troposphere.

Two dates (January 26 and 31) are worth mentioning since they correspond to periods when radiosondes and HAMSTRAD agree better. On January 26 around 04:00 UTC, the radiometer's data acquisition system was entirely rebooted, and the observation window was changed from blue foam to LD24. These two changes have resulted in vertical profiles of $\mathrm{H}_{2} \mathrm{O}$ from HAMSTRAD very close to radiosondes, particularly on January 26. Later on, the bias relative to radiosondes still persists but is less intense than prior to January 26. On January 31, a major blackout, namely, a long power failure, occurred at the station prior to 12:00 UTC. Again, the radiometer's data acquisition system was rebooted, and the vertical profiles of $\mathrm{H}_{2} \mathrm{O}$ from HAMSTRAD were again very close to the radiosondes, particularly on January 31 . This phenomenon associated 


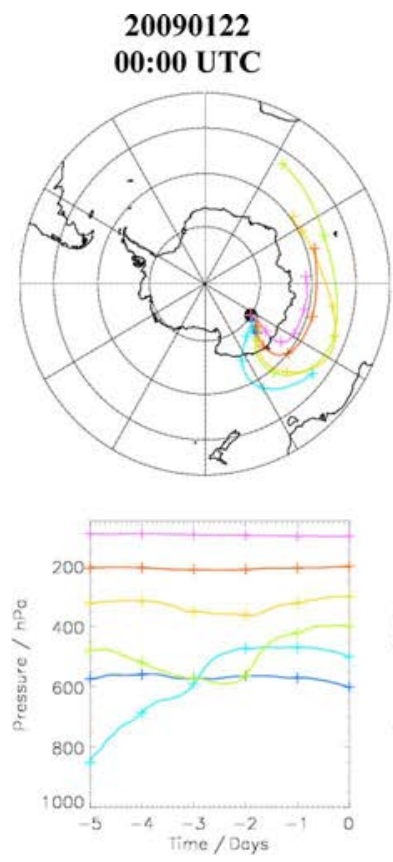

20090127 00:00 UTC
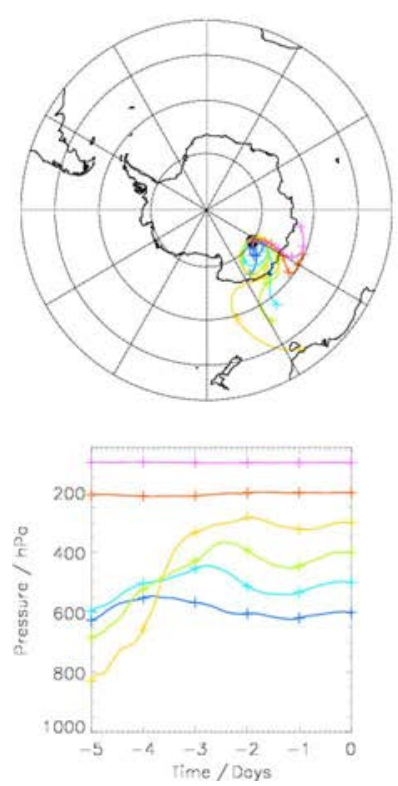

20090123

00:00 UTC
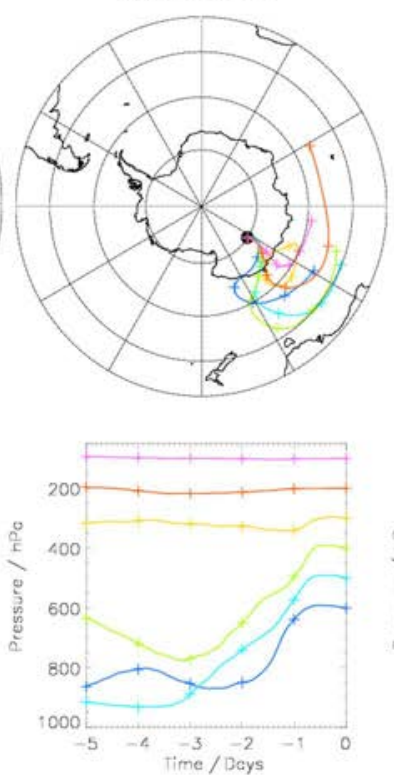

20090128

00:00 UTC
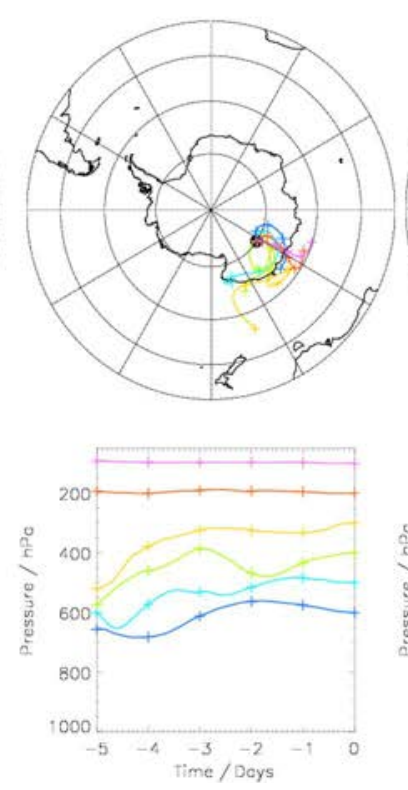
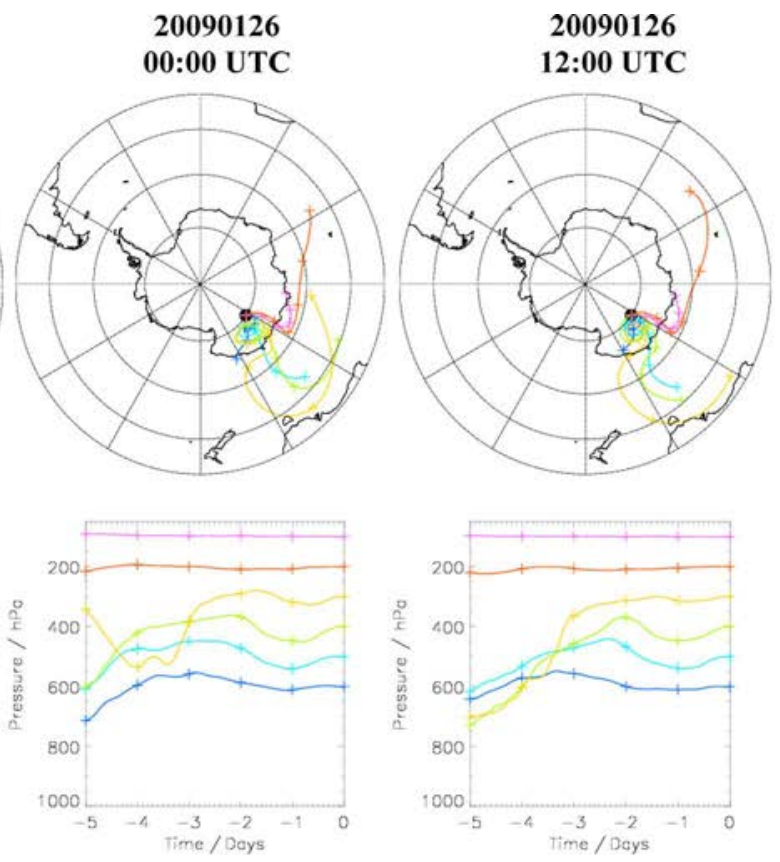

20090129

00:00 UTC

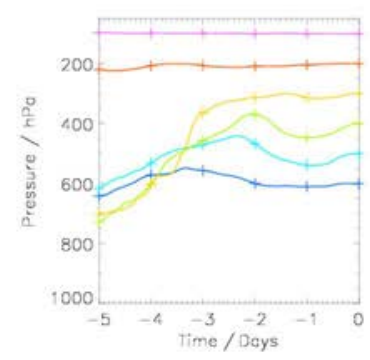

20090130

00:00 UTC
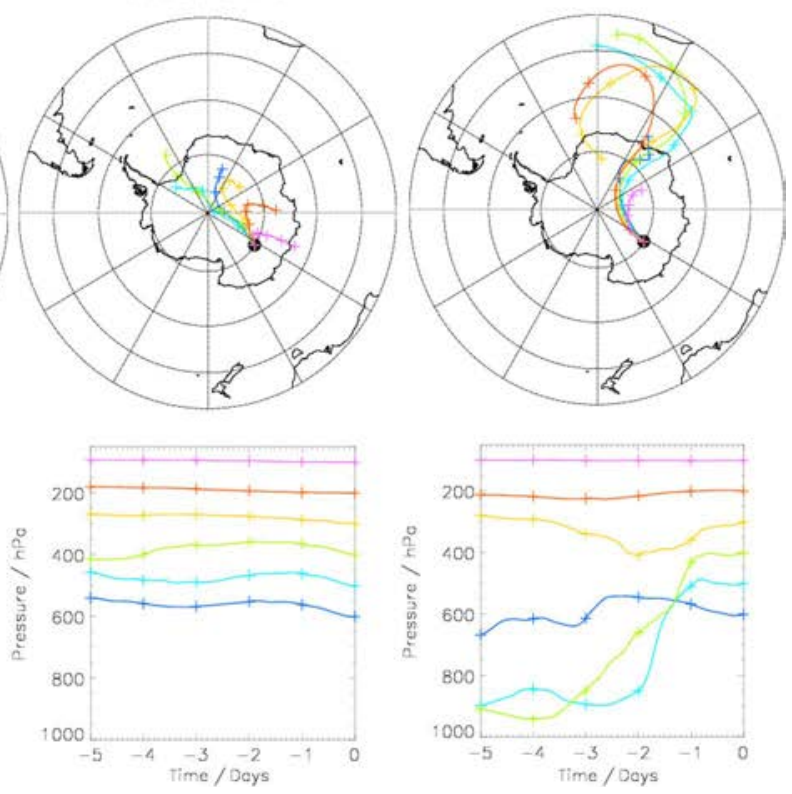

Fig. 6. (From top to bottom and from left to right) Maps of the 5-day back trajectories calculated from the Dome-C site at five different pressure levels: (dark blue line) $600 \mathrm{hPa}$, (light blue line) $500 \mathrm{hPa}$, (green line) $400 \mathrm{hPa}$, (yellow line) $300 \mathrm{hPa}$, (red line) $200 \mathrm{hPa}$, and (pink line) $100 \mathrm{hPa}$ starting on January 22,23 , and 26, 2009 at 00:00 UTC and January 26 at 12:00 UTC (top) and from January 27, 28, 29, and 30, 2009 at 00:00 UTC. The black filled circle represents the location of the Dome-C site. Crosses on each 5-day back trajectory represent the location of the air parcel 1, 2, 3, 4, and 5 days before reaching the Dome-C station. (Bottom, from left to right) Pressure versus time of the 5-day back trajectories calculated from the Dome-C site at five different pressure levels: (dark blue line) $600 \mathrm{hPa}$, (light blue line) $500 \mathrm{hPa}$, (green line) $400 \mathrm{hPa}$, (yellow line) $300 \mathrm{hPa}$, (red line) $200 \mathrm{hPa}$, and (pink line) $100 \mathrm{hPa}$ starting on January $22,28,29$, and 30, 2009 at 00:00 UTC. Crosses on each 5-day back trajectory represent the location of the air parcel 1, 2, 3, 4, and 5 days before reaching the Dome-C station.

with blackouts at the station has been also observed during the 2010 summer campaign. We are currently analyzing this feature that seems to disappear when we systematically reboot the radiometer's data acquisition system after any major blackout. Based upon our expertise from more than one year of data measurement from HAMSTRAD at Dome C (from January 2010 continuously to date), one indication of the drift in the $\mathrm{H}_{2} \mathrm{O}$ receiver apparently solved by sporadic major blackouts could be due to the instability of the noise diode that is used to perform the automated calibration of spectra at high frequency (once per minute). An empirical way to partially solve the problem has been found by rebooting the system on a regular weekly basis.

\section{Temporal Evolution}

We now study in detail the time variation of the $\mathrm{H}_{2} \mathrm{O}$ as measured by HAMSTRAD in the PBL ( 0 and $50 \mathrm{~m}$ above surface), 

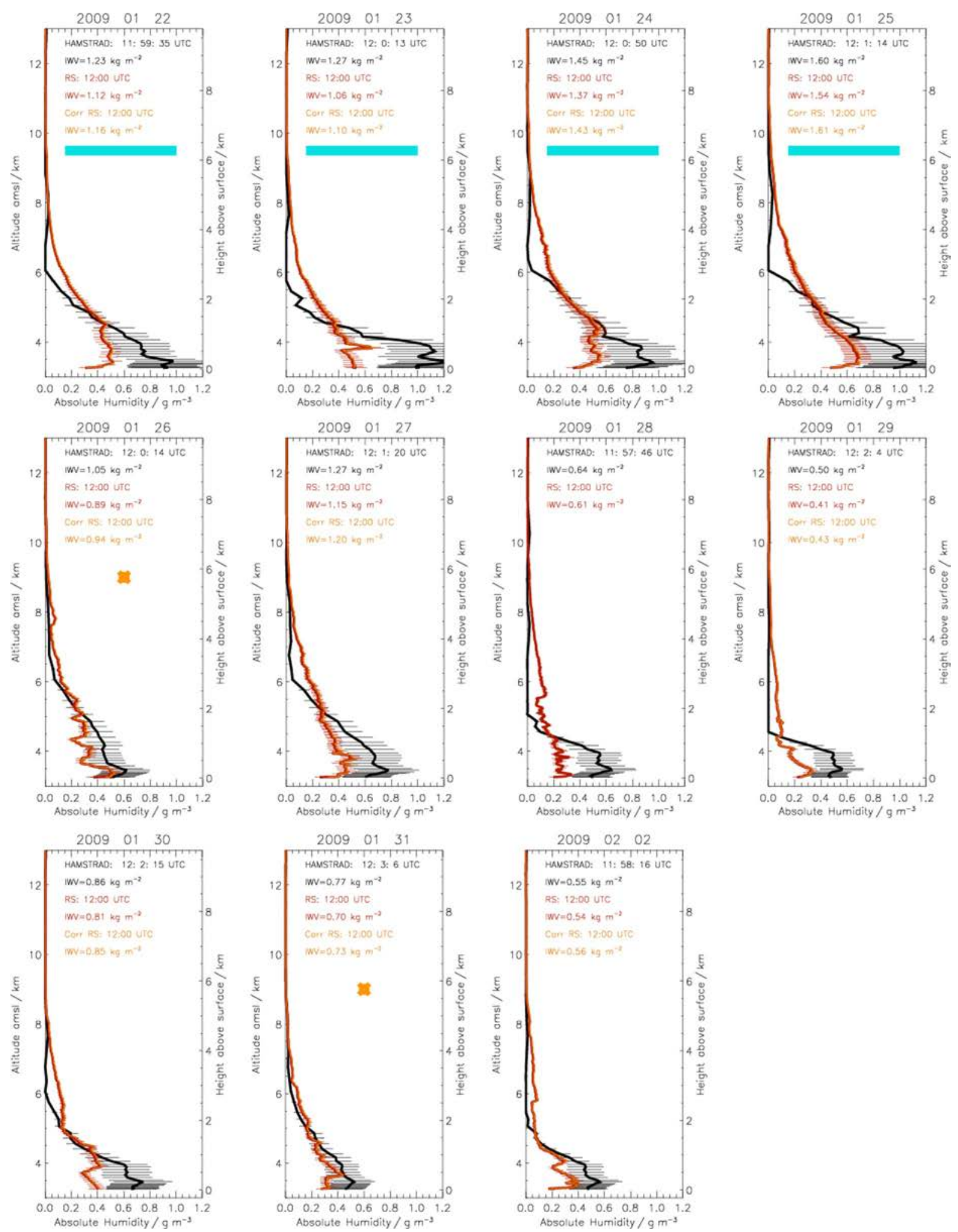

Fig. 7. Vertical profiles of absolute humidity as measured by (black line) HAMSTRAD, (red line) the radiosondes, and (orange line) the corrected radiosondes above Dome C from January 22 to February 2, 2009. Note that no radiosounding was performed on February 1, 2009, and the corrected radiosonde is not available on January 28, 2009. The light blue horizontal thick line represents the period from January 22 to 26 at 04:00 UTC when a blue foam was attached to the HAMSTRAD observation window. The two orange crosses represent the dates when a major reboot has been performed.

in the free troposphere (550 and $2000 \mathrm{~m}$ above surface), and around the tropopause (5000 $\mathrm{m}$ above surface).

1) $P B L$ : The temporal evolution of $\mathrm{H}_{2} \mathrm{O}$ measured at the surface and $50 \mathrm{~m}$ above surface by HAMSTRAD is represented in Fig. 8. We also show measurements by the radiosondes, by the Humicap sondes from LGGE, and by IASI. The information from the in situ meteorological sensor attached to HAMSTRAD is also plotted, only for the surface. Note that a comprehensive 

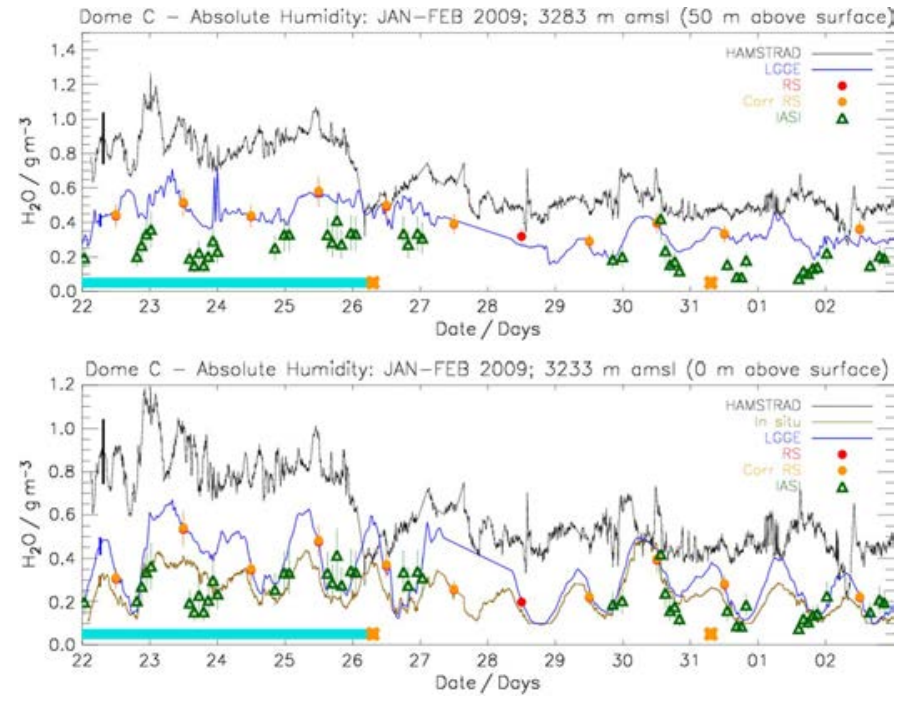

Fig. 8. Temporal evolution of absolute humidity as measured by (black line) HAMSTRAD, (red filled circles) the radiosondes, (orange filled circles) the corrected radiosondes, (blue line) the LGGE Humicap sondes, (green thick triangles) IASI, and (brown line) the in situ HAMSTRAD sensor at (top) $50 \mathrm{~m}$ above surface and at (bottom) the surface of the Dome-C station from January 22 to February 2, 2009. The vertical error bars associated to each data set represent the $3-\sigma$ error, except that, for HAMSTRAD, HAMSTRAD meteorological sensor, and in situ LGGE sensor and for the sake of clarity, only one vertical bar is represented (thick line) on January 22, 2009. The light blue horizontal bar represents the period from January 22 to 26 at 04:00 UTC when a blue foam was attached to the HAMSTRAD observation window. The two orange crosses represent the dates when a major reboot has been performed.

study of the diurnal variations of $\mathrm{H}_{2} \mathrm{O}$ and temperature in the PBL based upon HAMSTRAD and in situ sensors together with ECMWF analyses from January to June 2010 has been already presented in [14]. Consequently, we will not study in detail the evolution of $\mathrm{H}_{2} \mathrm{O}$ as measured by HAMSTRAD during the 12-day period. The HAMSTRAD absolute humidity at the surface shows a net decrease from January 22 to 28 , then stabilizes until the end of the period, from about 1 to $0.5 \mathrm{~g} \cdot \mathrm{m}^{-3}$. A net dip is observed on January 26 , and a prominent bump is measured near the end of January 22 to the beginning of January 23 . The same behavior is observed at $50 \mathrm{~m}$ above the surface. The other measurements show a smaller decrease of the surface $\mathrm{H}_{2} \mathrm{O}$ of about $0.2 \mathrm{~g} \cdot \mathrm{m}^{-3}$ over the entire period than HAMSTRAD. The radiosondes and the Humicap LGGE are somehow wetter than the IASI and in situ HAMSTRAD by about $0.2 \mathrm{~g} \cdot \mathrm{m}^{-3}$, with a difference almost vanishing at the end of the period.

The origin of air masses (see Fig. 6) can explain the variability of $\mathrm{H}_{2} \mathrm{O}$ in the PBL over the 12-day period under consideration. Air parcels at 600 and $500 \mathrm{hPa}$ are mainly coming from the Antarctic coast $\left(60^{\circ} \mathrm{S}-70^{\circ} \mathrm{S}, 30^{\circ} \mathrm{E}-150^{\circ} \mathrm{E}\right)$ and the oceanic midlatitude band $\left(60^{\circ} \mathrm{S}-45^{\circ} \mathrm{S}\right.$, eastward from $0^{\circ}$ to $180^{\circ}$ ), respectively, except on January 29 when air masses transit over the Antarctic Plateau, explaining the minimum in $\mathrm{H}_{2} \mathrm{O}$ observed by the radiosondes and the in situ sensors. The increase in $\mathrm{H}_{2} \mathrm{O}$ observed by HAMSTRAD on January 23 can be explained by an unusual 600 -hPa trajectory initiated at $50^{\circ} \mathrm{S}$ and $120^{\circ} \mathrm{E}$ in the midlatitudes. Consequently, HAMSTRAD is sensitive to $\mathrm{H}_{2} \mathrm{O}$ in the PBL, but some issues need to be discussed. First, regarding the abrupt jump of $\mathrm{H}_{2} \mathrm{O}$ in HAMSTRAD on January 26 between 00:00 and 12:00 UTC and not observed in the other data sets, this cannot be attributed
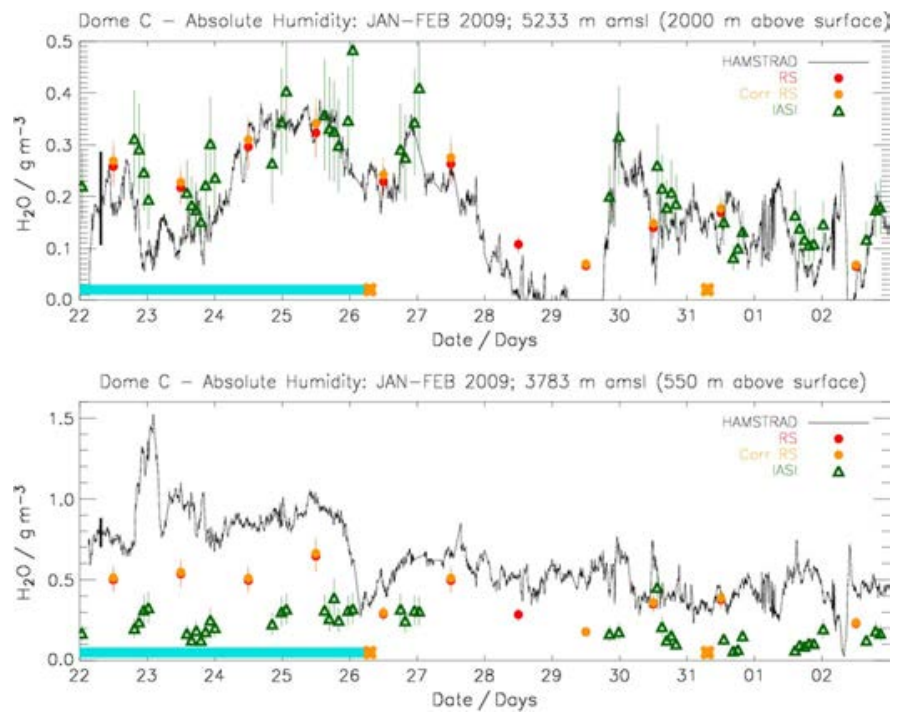

Fig. 9. As in Fig. 8, but for (black line) HAMSTRAD, (red filled circles) the radiosondes, (orange filled circles) the corrected radiosondes, and (green thick triangles) IASI at the altitude of (bottom) 550 and $2000 \mathrm{~m}$ above surface from January 22 to February 2, 2009.

to any dramatic change in the origin of air masses, neither at $600 \mathrm{hPa}$ nor at $500 \mathrm{hPa}$ (see Fig. 6). Two different conditions of observation happened on that period: 1) the change between blue and white foams and 2) a major blackout at the station. As already mentioned in the previous section, the use of a blue foam has impacted the calibration of spectra and, in the PBL, has artificially increased $\mathrm{H}_{2} \mathrm{O}$ by $\sim 5 \%-10 \%$. The major blackouts of January 26 and 31 and the major following reboots have positively impacted the vertical distribution of $\mathrm{H}_{2} \mathrm{O}$ by producing HAMSTRAD profiles much closer to the radiosondes (see Fig. 7). Second, the apparent loss of sensibility of HAMSTRAD close to the surface might certainly come from the vertical resolution of the $\mathrm{H}_{2} \mathrm{O}$ measurements that can be estimated to be $30-50 \mathrm{~m}$ (see Appendix and [14]). Since the diurnal amplitude decreases with height, we can then expect to remotely measure weaker amplitudes compared with the in situ sensors. Third, the vertical resolution of HAMSTRAD cannot explain the systematic wet bias (whatever the period and the foam considered) of more than $0.3-0.5 \mathrm{~g} \cdot \mathrm{m}^{-3}$ in the PBL relative to all the other data sets, bias that is consistent with the 2010 HAMSTRAD measurements [14], [24].

2) Free Troposphere: The temporal evolution of $\mathrm{H}_{2} \mathrm{O}$ measured at 550 and $2000 \mathrm{~m}$ above surface by HAMSTRAD is represented in Fig. 9. We also show the evolution of $\mathrm{H}_{2} \mathrm{O}$ as measured by the radiosondes and IASI. Note that, from [14], the top of the PBL in the summer season shows a large dayto-day variability from $\sim 50 \mathrm{~m}$ up to $\sim 1000 \mathrm{~m}$. The level of $2000 \mathrm{~m}$ above surface is definitively in the free troposphere. However, the level of $550 \mathrm{~m}$ above surface, although well above the 200-m average height generally attributed to the top of the PBL [2] at Dome C, thus generally in the free troposphere, can nevertheless be in the PBL. Indeed, in January-February 2009, these two altitude levels show two different regimes in the evolution of $\mathrm{H}_{2} \mathrm{O}$.

At $550 \mathrm{~m}$ above surface, HAMSTRAD shows a temporal evolution consistent enough with the evolution in the PBL, 
namely, a decrease throughout the entire period from about 0.9 to $0.4 \mathrm{~g} \cdot \mathrm{m}^{-3}$, with an obvious dip on January 26 and a sharp bump on January 22-23. The temporal evolution of $\mathrm{H}_{2} \mathrm{O}$ as detected from the radiosondes is rather consistent with HAMSTRAD but tends to show a wet bias in the HAMSTRAD data set, of about $0.2-0.3 \mathrm{~g} \cdot \mathrm{m}^{-3}$ before January 26 , reduced to $0.1-0.2 \mathrm{~g} \cdot \mathrm{m}^{-3}$ after that date (imprint of the use of blue foam on the $\mathrm{H}_{2} \mathrm{O}$ calibration thus on the $\mathrm{H}_{2} \mathrm{O}$ retrieval). The dip on January 26 observed by HAMSTRAD is also present in the radiosonde data set, but the strong bump on January $22-23$ is absent since it did not overlap with the observational sampling of the radiosondes at 12:00 UTC. Again, this bump is attributable to the $400-\mathrm{hPa}$ air mass history originating from midlatitudes $\left(45^{\circ} \mathrm{S}, 100^{\circ} \mathrm{E}\right)$ at $600 \mathrm{hPa}$ and dipping down to $800 \mathrm{hPa}$ when reaching the south of Tasmania. There is an obvious dry bias of IASI relative to HAMSTRAD of about $0.6-0.8 \mathrm{~g} \cdot \mathrm{m}^{-3}$, with a slight negative slope of IASI data throughout the entire period, and also a dry bias relative to the radiosondes that is far from negligible $\left(0.2-0.3 \mathrm{~g} \cdot \mathrm{m}^{-3}\right)$. Note that the IASI vertical resolution of about $1.5 \mathrm{~km}$ in the free troposphere (see Table I) produces a systematic dry bias on the $\mathrm{H}_{2} \mathrm{O}$ profile of $\sim 5 \%$ at $550 \mathrm{~m}$ (see Appendix) that is much less than the observed bias with the radiosondes. Regarding HAMSTRAD, we can again note two points: 1) At this altitude, the use of the plate (blue versus white foams) of the observation window still impacts the HAMSTRAD $\mathrm{H}_{2} \mathrm{O}$ amounts being in better agreement with the other measurements after January 26, and 2) the $\mathrm{H}_{2} \mathrm{O}$ amounts are very consistent with the radiosondes just after the radiometer's data acquisition system has been rebooted (January 26 and 31).

At $2000 \mathrm{~m}$ above surface, the time evolution of $\mathrm{H}_{2} \mathrm{O}$ as measured by HAMSTRAD differs from the one at $550 \mathrm{~m}$ above surface. Indeed, the variability in the $\mathrm{H}_{2} \mathrm{O}$ amount as measured by HAMSTRAD is much greater than in the PBL and at $550 \mathrm{~m}$ above surface. From January 22 , there is first a rapid decrease in absolute humidity from 0.2 to $0.1 \mathrm{~g} \cdot \mathrm{m}^{-3}$ to the beginning of January 23, then a slow increase to $0.33 \mathrm{~g} \cdot \mathrm{m}^{-3}$ on January 25 and a slow decrease to very small values on January 29. Note that retrieved values are actually zero for some hours on January 29. Prior to January 28, the difference between corrected and uncorrected radiosondes starts being nonnegligible at this level, namely, $\sim 0.02 \mathrm{~g} \cdot \mathrm{m}^{-3}$. On January 30 , $\mathrm{H}_{2} \mathrm{O}$ rapidly jumps to $0.3 \mathrm{~g} \cdot \mathrm{m}^{-3}$ and continues decreasing to $0.1 \mathrm{~g} \cdot \mathrm{m}^{-3}$ at the end of the period. The time evolution of the radiosondes is very consistent with HAMSTRAD: dips on January 23 and 29 and a bump on January 25 . The moderate and strong increases in $\mathrm{H}_{2} \mathrm{O}$ as deduced from HAMSTRAD on January 27 and 30, respectively, are unfortunately not sampled by the radiosondes. On January 27 , the $300-\mathrm{hPa}$ air mass is originating from midlatitudes in the vicinity of Tasmania at a very high pressure level, namely, $850 \mathrm{hPa}$. On January 30 , the $300-\mathrm{hPa}$ air mass, although originating from the Antarctic plateau, propagates toward midlatitudes down to a pressure level of $\sim 400 \mathrm{hPa}$. These two particular spikes are also observed within the cloud-free IASI data set, together with the general shape of the temporal evolution. IASI shows higher water amounts than HAMSTRAD and radiosondes at this level.

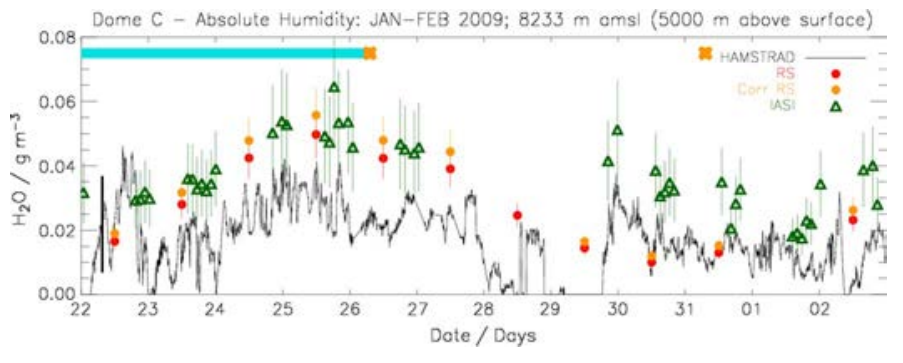

Fig. 10. As in Fig. 8, but for (black line) HAMSTRAD, (red filled circles) the radiosondes, (orange filled circles) the corrected radiosondes, and (green thick triangles) IASI at $5000 \mathrm{~m}$ above surface from January 22 to February 2, 2009.

The two periods related to a change in the foam of the HAMSTRAD observation window (January 26) and a massive blackout (January 31) are no longer associated with any abrupt change in the $\mathrm{H}_{2} \mathrm{O}$ temporal evolution. This apparent general agreement between HAMSTRAD and the other instruments might just be an artifact from the general shape of the HAMSTRAD vertical profiles (see Figs. 7 and 11). Indeed, below $\sim 2000 \mathrm{~m}$ above surface, HAMSTRAD systematically measures a wet atmosphere and conversely above. A last point worth mentioning is that the abrupt decrease in $\mathrm{H}_{2} \mathrm{O}$ observed at $2000 \mathrm{~m}$ above surface by radiosondes and HAMSTRAD from January 27 to 29 is also associated with the presence of clouds over the Dome-C station (probably thick and over a wide area) because IASI cannot provide any cloud-free measurement of humidity.

3) Tropopause: The level of $5000 \mathrm{~m}$ above surface $(8233 \mathrm{~m}$ amsl) is representative of the tropopause region (see Fig. 12). When considering the radiosonde temperature profiles from January 22 to 28 , this layer is mainly in the upper troposphere (1-2 km below the tropopause), whereas during the remaining period, the layer is $0.5 \mathrm{~km}$ below or above the tropopause, and on January 30, the layer is even in the lower stratosphere. The temporal evolution of $\mathrm{H}_{2} \mathrm{O}$ as measured by HAMSTRAD at $5000 \mathrm{~m}$ above surface is presented in Fig. 10.

The evolution of $\mathrm{H}_{2} \mathrm{O}$ as measured by HAMSTRAD over the 12-day period at $5000 \mathrm{~m}$ above surface is very similar to the one at $2000 \mathrm{~m}$ above surface (maxima on January 22, 25, and 30 and minima on January 23 and 29), but the amount of $\mathrm{H}_{2} \mathrm{O}$ dramatically decreased to a maximum of $0.04 \mathrm{~g} \cdot \mathrm{m}^{-3}$. The general evolution of $\mathrm{H}_{2} \mathrm{O}$ is also consistent with the radiosondes, but the radiosondes are wetter by $0.01 \mathrm{~g} \cdot \mathrm{m}^{-3}$ prior to January 29 and in agreement with HAMSTRAD after. The corrected radiosondes are much wetter than the uncorrected ones by $0.005-0.010 \mathrm{~g} \cdot \mathrm{m}^{-3}$. The IASI data set is wetter by $0.01 \mathrm{~g} \cdot \mathrm{m}^{-3}$ than HAMSTRAD throughout the entire period, but again, the general evolution of $\mathrm{H}_{2} \mathrm{O}$ is well correlated with HAMSTRAD. Note that, considering the vertical resolution of IASI in the upper troposphere/lower stratosphere $(\sim 2 \mathrm{~km})$, the amount of $\mathrm{H}_{2} \mathrm{O}$ from radiosondes degraded to 2-km resolution should be $10 \%-15 \%$ (see Appendix) greater than the highresolution radiosondes. This value is thus less than the observed wet bias of IASI versus radiosondes $(\sim 25 \%)$.

As at $2000 \mathrm{~m}$ above surface, the HAMSTRAD time variation does not show any abrupt change on January 26 and 31, when a change in the foam of the HAMSTRAD observation window 
and a massive blackout, respectively, occurred. The abrupt decrease in $\mathrm{H}_{2} \mathrm{O}$ observed by radiosondes and HAMSTRAD from January 27 to 29 is also associated with the presence of clouds over the Dome-C station. Since the vertical resolution of HAMSTRAD is expected to be $\sim 500 \mathrm{~m}$ in the upper troposphere/ lower stratosphere and since $\mathrm{H}_{2} \mathrm{O}$ amounts strongly drop above the tropopause, we can guess that the evolution of $\mathrm{H}_{2} \mathrm{O}$ as observed by HAMSTRAD at $5000 \mathrm{~m}$ above the surface is strongly weighted by the layers below the tropopause. The air masses at 200 and $100 \mathrm{hPa}$ over the 12-day period are strongly correlated with ocean origins over the period January 22-26 and January 31-February 2 and Antarctic origins during the period January 27-30. Furthermore, the period January 24-27 when $\mathrm{H}_{2} \mathrm{O}$ amount shows a wide maximum corresponds to a time frame when the level of $5000 \mathrm{~m}$ above surface is well below the tropopause by $\sim 2 \mathrm{~km}$. Finally, considering the HAMSTRAD data set spanning only over a 12 -day period in 2009 , the measurements suggest that the instrument is sensitive to the upper tropospheric layers. This is consistent with the conclusions drawn from the 2010 HAMSTRAD data set [24].

\section{Statistical Analysis}

Here, we perform a statistical analysis of all the absolute humidity fields measured by HAMSTRAD, radiosondes, IASI, and in situ sensors (Humicap LGGE and HAMSTRAD) considering means and standard deviations during the period January 22-February 2, 2009. Furthermore, we also calculate biases and linear Pearson correlation coefficients of radiosondes, IASI, and in situ sensor (Humicap LGGE and HAMSTRAD) measurements with respect to coincident HAMSTRAD measurements during the same period. All the levels are separately treated. Means, standard deviations, biases, and correlations are presented in Fig. 11.

First of all, the vertical distribution of $\mathrm{H}_{2} \mathrm{O}$ averaged over the 12-day period above Dome $\mathrm{C}$ is different depending on the data set considered (Fig. 11, top left and bottom left). Consistently with the previous sections, we can note that HAMSTRAD is wetter by $0.2 \mathrm{~g} \cdot \mathrm{m}^{-3}$ than the radiosondes from the surface to about $2 \mathrm{~km}$, and the radiosondes are wetter than IASI by about $0.10-0.15 \mathrm{~g} \cdot \mathrm{m}^{-3}$. There is a small difference along the vertical between the corrected and uncorrected radiosondes, with the corrected being always wetter than the uncorrected by $0.005-0.01 \mathrm{~g} \cdot \mathrm{m}^{-3}$. The Humicap LGGE $\mathrm{H}_{2} \mathrm{O}$ is consistent with the radiosondes, whereas the in situ meteorological sensor from HAMSTRAD compares very well with IASI. Above $\sim 2-\mathrm{km}$ altitude, HAMSTRAD is drier by $0.1 \mathrm{~g} \cdot \mathrm{m}^{-3}$ than radiosondes that are drier than IASI by $0.05 \mathrm{~g} \cdot \mathrm{m}^{-3}$. As we already noticed in the previous sections, for two dates (January 26 and 31), HAMSTRAD and radiosondes were close together within the troposphere. Despite the fact that IASI and radiosondes cannot sound the atmosphere at the same time, this particular study based upon HAMSTRAD measurements sampling the full diurnal cycle at Dome $\mathrm{C}$ does show that IASI is drier than radiosondes by $0.1-0.2 \mathrm{~g} \cdot \mathrm{m}^{-3}$ for heights less than $2 \mathrm{~km}$ above surface and is slightly wetter than radiosondes by $0.05 \mathrm{~g} \cdot \mathrm{m}^{-3}$ for heights greater than $2 \mathrm{~km}$ above surface.
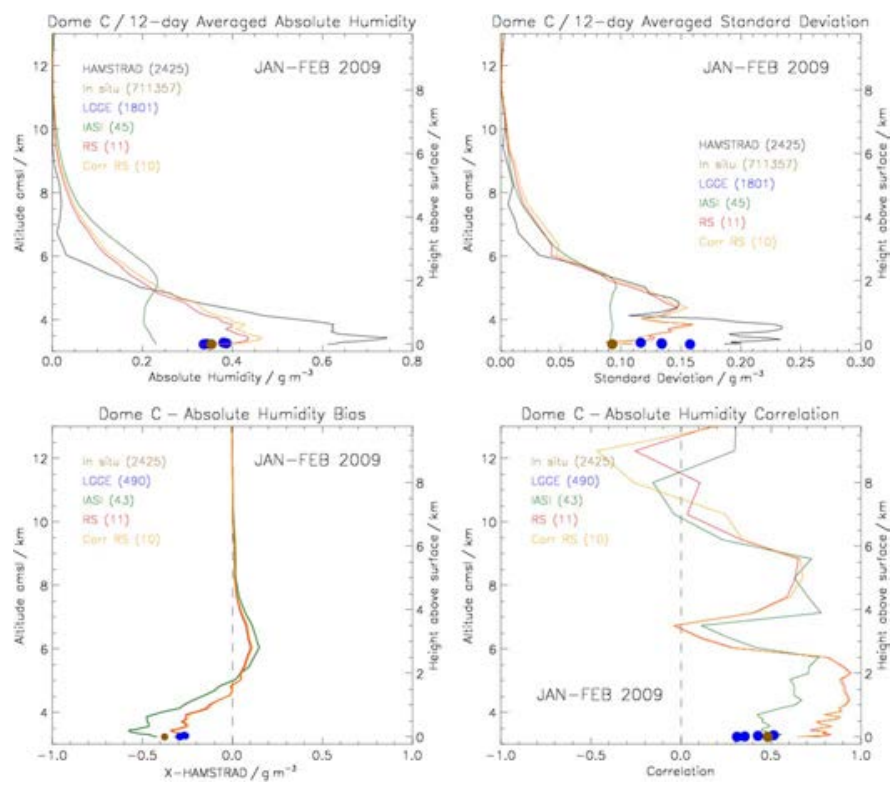

Fig. 11. (Top left) Vertical profiles of absolute humidity as measured by (black line) HAMSTRAD, (filled brown circles) in situ, (green line) IASI, (red line) the radiosondes, (orange line) the corrected radiosondes, and (filled blue circles) the LGGE Humicap sondes above the Dome-C station averaged from January 22 to February 2, 2009. (Top right) Same as top left except for the absolute standard deviation $\left(\mathrm{g} \cdot \mathrm{m}^{-3}\right)$. (Bottom left) Same as top left except for the bias between all the data sets and HAMSTRAD $\left(\mathrm{g} \cdot \mathrm{m}^{-3}\right)$. (Bottom right) Same as top left except for the correlation between all the data sets and HAMSTRAD. The number of profiles or points used in the averaging is noted in parentheses for each set of data. Moreover, note that bias and correlation versus HAMSTRAD are calculated in time coincidence explaining why the number of measurements used in the statistics is less than when calculating mean and standard deviation.

For heights less than $1 \mathrm{~km}$ above surface, the standard deviation calculated over the 12-day period (Fig. 11, top right) is greater in the HAMSTRAD data set $\left(0.2 \mathrm{~g} \cdot \mathrm{m}^{-3}\right)$ than in radiosondes and Humicap LGGE data $\left(0.12-0.15 \mathrm{~g} \cdot \mathrm{m}^{-3}\right)$ and in IASI and in situ HAMSTRAD data $\left(\sim 0.09 \mathrm{~g} \cdot \mathrm{m}^{-3}\right)$. For heights greater than $1 \mathrm{~km}$ above surface, HAMSTRAD and radiosonde standard deviations are consistent, within a domain between 2 and $3 \mathrm{~km}$ above surface where three data sets (HAMSTRAD, IASI, and radiosonde) show the same standard deviation.

Finally, the linear Pearson correlation coefficient between all the other data sets and HAMSTRAD in temporal coincidence is very instructive (Fig. 11, bottom right). For heights less than $2.5 \mathrm{~km}$ above surface, radiosonde and HAMSTRAD data sets are well correlated from 0.75 at the surface up to $0.8-0.9$ at $2.5 \mathrm{~km}$ above surface. The in situ data (Humicap LGGE and HAMSTRAD meteorological sensor) are not so well correlated with HAMSTRAD (0.5-0.7), probably showing the weak sensitivity of HAMSTRAD to sound the surface atmosphere and to detect the strong diurnal cycle in humidity. IASI is also weakly correlated with HAMSTRAD in the lowermost troposphere but is comparable to radiosondes at $2.5 \mathrm{~km}$ above surface (0.7). There is a vertical domain centered around $3.5 \pm 2 \mathrm{~km}$ above surface where IASI and radiosondes are not correlated with HAMSTRAD $(<0.5)$. Finally, between 3.5 and $6 \mathrm{~km}$ above surface ( $\sim 6-9 \mathrm{~km}$ amsl), HAMSTRAD's correlation with IASI and radiosondes is rather weak (0.45-0.75). 

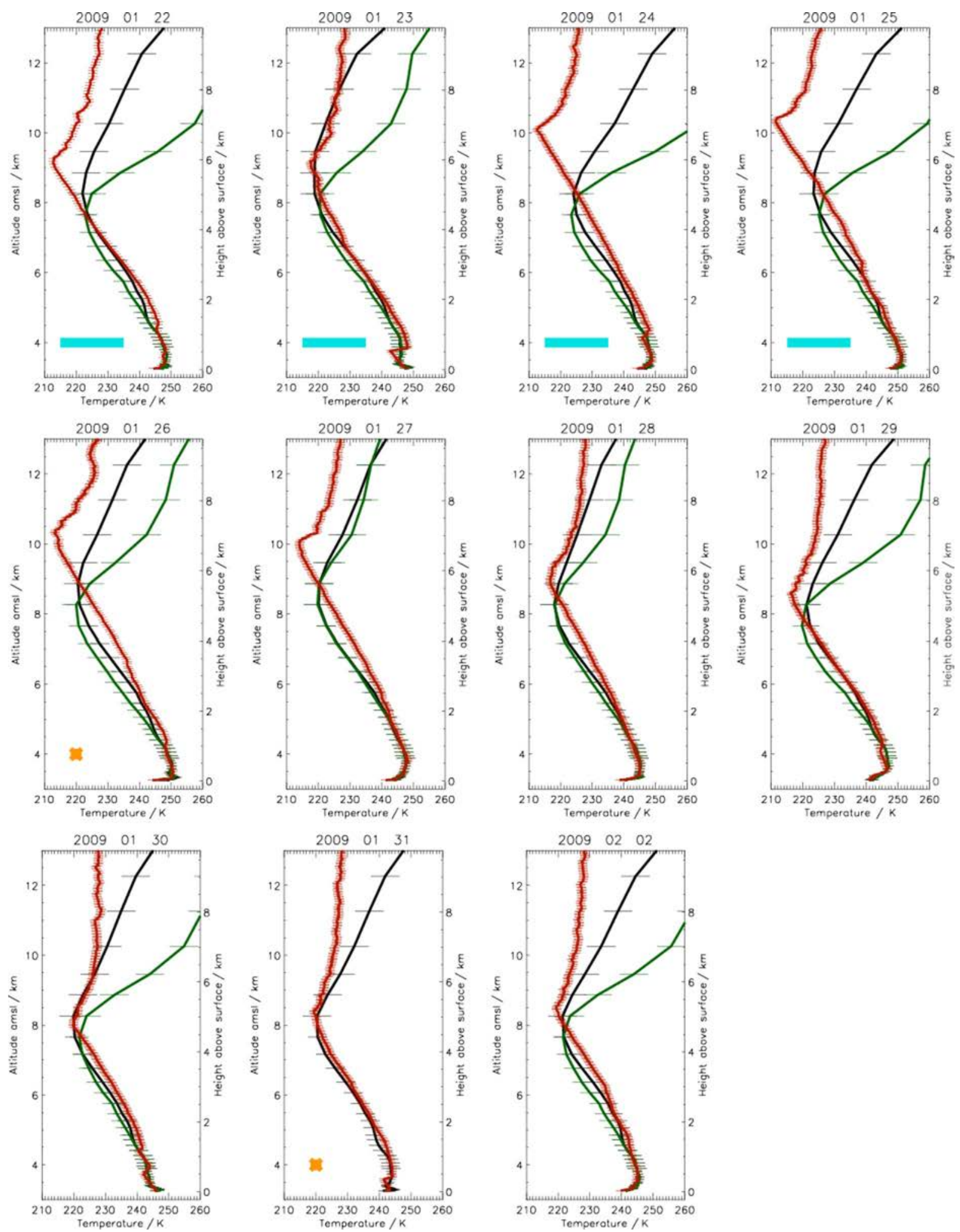

Fig. 12. Vertical profiles of temperature as measured by HAMSTRAD in (black line) full troposphere and (green line) boundary layer modes and the (red) radiosondes above Dome C from January 22 to February 2, 2009. Note that no radiosounding was performed on February 1, 2009. The light blue horizontal thick line represents the period from January 22 to 26 at 04:00 UTC when a blue foam was attached to the HAMSTRAD observation window. The two orange crosses represent the dates when a major reboot has been performed.

In conclusion, the measurements of absolute humidity from HAMSTRAD at Dome $\mathrm{C}$ tend to cover a wide vertical range from the surface to about 4-6 km above surface, namely, from the PBL to the tropopause, with a high sensitivity in the free troposphere. Compared with radiosondes, a good agreement has been found for IWV, whereas the $\mathrm{H}_{2} \mathrm{O}$ vertical profile shape is not well reproduced by HAMSTRAD, which is likely due to problems with the calibration and profile retrieval methodology. The temporal evolution of $\mathrm{H}_{2} \mathrm{O}$ is, in general, well represented by HAMSTRAD at all levels within the limits of the 
measurement noise, a consequence of the instrument good temporal sampling capability.

\section{TEMPERATURE}

\section{A. Vertical Profiles}

The vertical distribution of temperature as measured by HAMSTRAD from January 22 to February 2, 2009 in temporal coincidence with the radiosondes launched at 12:00 UTC above the Dome-C site is shown in Fig. 12. Again, note that no radiosonde launch was performed on February 1, 2009. The two modes of observation are presented for temperature: the boundary layer and the full troposphere modes. In the following sections, a temperature composite profile will be presented that is a combination of temperature measurements in the boundary layer and full troposphere modes, with a strong weighting of boundary layer mode in the lowermost troposphere and a strong weighting of full troposphere mode above.

Throughout the 12-day period (except on January 23), in the lowermost troposphere for heights less than $500 \mathrm{~m}$ above surface, the boundary layer temperature profiles mimic very well the profiles measured by the radiosondes, regardless of the sign of the vertical gradient (either positive or negative). Above $500 \mathrm{~m}$ up to $5 \mathrm{~km}$ above surface (around the tropopause, namely, 8-9 $\mathrm{km} \mathrm{amsl),} \mathrm{the} \mathrm{full} \mathrm{troposphere} \mathrm{temperature}$ profile has a cold bias from 1 to $5 \mathrm{~K}$ compared with the radiosondes, but for some dates (January 23, 29, and 31), the full troposphere temperature is very close to the radiosonde temperature. The location and temperature of the tropopause as detected by HAMSTRAD are usually both considerably lower (by 1-2 km) and warmer than the radiosondes. However, on some occasions, as on January 23, 30, and 31, HAMSTRAD does reproduce the temperature and the altitude of the tropopause as detected by the radiosondes, probably because these dates correspond to a low tropopause height, and thus, the deviations to HAMSTRAD are not too pronounced. Above, in the stratosphere, the full troposphere profile is much warmer than the radiosonde profiles by $10-20 \mathrm{~K}$ except on two dates (January 23 and 28) when HAMSTRAD and radiosondes compare very well. The sensitivity of HAMSTRAD measurements in the lower stratosphere is rather weak over the 12-day period, but on some occasions, HAMSTRAD can detect a tropopause at $\sim 9.5 \mathrm{~km}$ amsl $(\sim 220 \mathrm{~K})$ on January 23 and at $\sim 8.0 \mathrm{~km}$ amsl ( $\sim 222 \mathrm{~K})$ on January 30, in agreement with radiosondes, namely, up to $2 \mathrm{~km}$ above the tropopause for these two dates. As already mentioned in Section II, the use of the blue or white foam does not affect the $60-\mathrm{GHz}$ channel retrieval, thus temperature. In addition, the two dates when a major reboot has been performed are not associated to any change in the vertical structure of the HAMSTRAD temperature, underlining that only the $183-\mathrm{GHz}$ channels are affected by the instability issues linked to the noise diode. Finally, as for $\mathrm{H}_{2} \mathrm{O}$, the present linear regression method to estimate temperature profiles is based upon radiosondes launched at the South Pole and the McMurdo stations. A new linear regression method recently developed using radiosondes launched at Dome C prior to 2009 does not
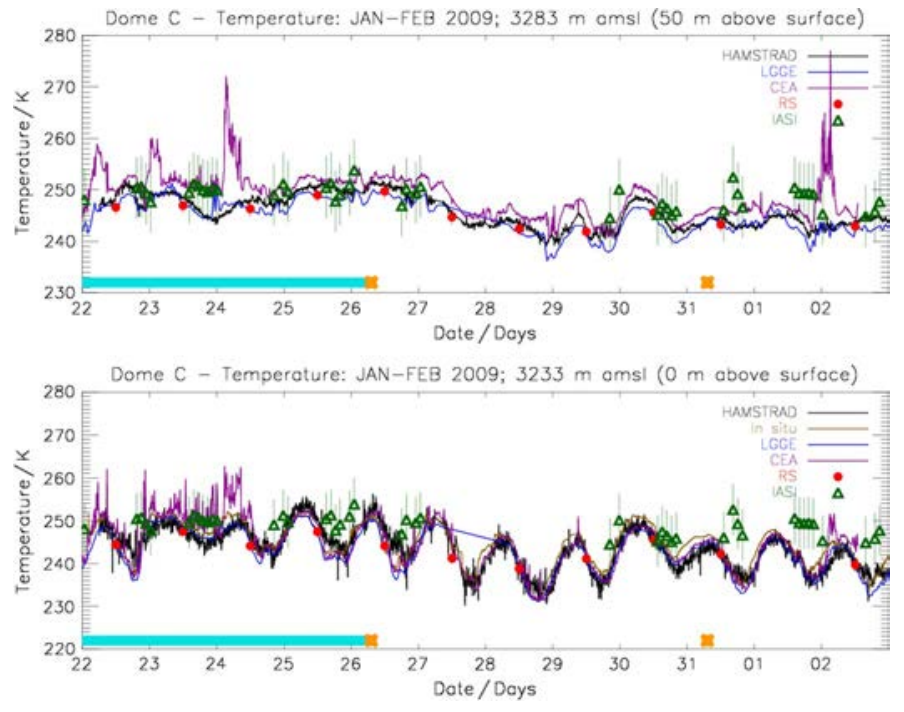

Fig. 13. Temporal evolution of temperature as measured by (black line) HAMSTRAD, (red filled circles) the radiosondes, (blue line) the LGGE PT100 sondes, (purple line) the CEA PT100 sondes, (green thick triangles) IASI, and (brown line) the in situ HAMSTRAD sensor at (top) $50 \mathrm{~m}$ above surface and at (bottom) the surface of the Dome-C station from January 22 to February 2, 2009. The vertical error bars associated to each data set represent the $3-\sigma$ error, except that, for HAMSTRAD, HAMSTRAD meteorological sensor, in situ LGGE, and CEA sensors and for the sake of clarity, only one vertical bar is represented (thick line) on January 22, 2009. The light blue horizontal bar represents the period from January 22 to 26 at 04:00 UTC when a blue foam was attached to the HAMSTRAD observation window. The two orange crosses represent the dates when a major reboot has been performed.

produce significantly different vertical profiles of temperature (not shown).

\section{B. Temporal Evolution}

As for $\mathrm{H}_{2} \mathrm{O}$, we now study in detail the time variation of the temperature as measured by HAMSTRAD in the PBL ( 0 and $50 \mathrm{~m}$ above surface), in the free troposphere (550 and $2000 \mathrm{~m}$ above surface), and around the tropopause $(5000 \mathrm{~m}$ above surface).

1) PBL: The temporal evolution of temperature measured by HAMSTRAD at the surface and $50 \mathrm{~m}$ above surface is represented in Fig. 13. We also show the variation of temperature as measured by the radiosondes, by the PT100 sondes from LGGE and CEA and by IASI. The information from the in situ meteorological sensor attached to HAMSTRAD is also presented, only at the surface. Note that, since a comprehensive study of the diurnal variation of temperature as measured by HAMSTRAD in the PBL over the period January-June 2010 has been presented in [14], we will not detail the time evolution of temperature below 50 m over 12 days in 2009 .

At the ground, the most intense signal detected by HAMSTRAD is the temperature diurnal variation with amplitude of $\pm 6-7 \mathrm{~K}$ that is also very well measured by the in situ HAMSTRAD and PT100 LGGE sensors. The atmosphere is warming from January 22 to 26 (from a maximum of 250 to $255 \mathrm{~K}$ ), then the temperature maximum decreases to $247 \mathrm{~K}$ on January 29 to stabilize until the end of the period. The PT100 CEA sensor generally measures the same variation except from January 22 to 24 and on February 2 when the variability of the data set 

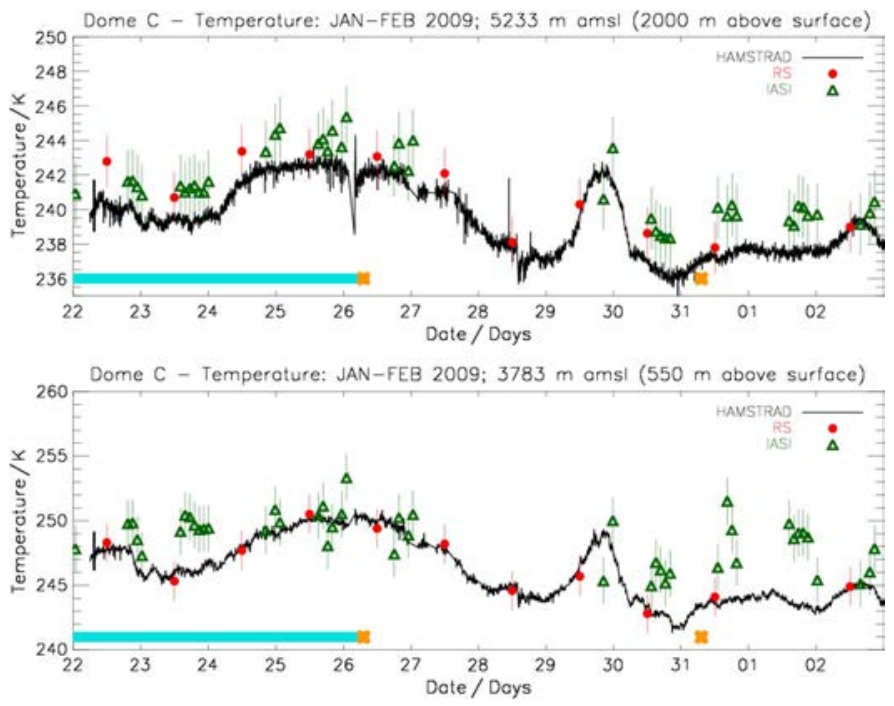

Fig. 14. As in Fig. 13, but for (black line) HAMSTRAD, (red filled circles) the radiosondes, and (green thick triangles) IASI at the altitude of (bottom) 550 and $2000 \mathrm{~m}$ above surface from January 22 to February 2, 2009.

exceeds the signal of the diurnal variation. During these two periods, wind amplitudes measured at Dome $\mathrm{C}$ were very low (not shown), and the PT100 CEA sensors did warm up since they are not force ventilated. The radiosonde measurements are in very good agreement with HAMSTRAD, the in situ PT100, and HAMSTRAD sensors. The IASI data set, at the surface, behaves relatively well although slightly warmer than all the other data sets by $2-5 \mathrm{~K}$, but some signatures of the diurnal variation can be seen from January 25 to 27 and on January 30 . In conclusion, the HAMSTRAD instrument is very sensitive to the surface temperature.

At $50 \mathrm{~m}$ above surface, the diurnal variation of temperature is very weak, almost absent from the HAMSTRAD data set, consistently with the radiosonde and the in situ PT100 LGGE and CEA data sets. From January 22 to 24 and on February 2 , the variability of the PT100 CEA data sets $(10-20 \mathrm{~K})$ is dramatically high, probably due to the signature of the warming effect of the sondes since they are not force ventilated. In general, IASI consistently behaves with all the other data sets, except maybe at the end of the period, but is weakly sensitive in the PBL due to its poor vertical resolution $(\sim 1 \mathrm{~km})$.

2) Free Troposphere: The temporal evolution of temperature measured at 550 and $2000 \mathrm{~m}$ above surface by HAMSTRAD is represented in Fig. 14. We also show the evolution of temperature as measured by the radiosondes and IASI. In contrast to what we observed for $\mathrm{H}_{2} \mathrm{O}$, these two altitudes show the same regime in the evolution of temperature, with a wide maximum centered on January $26(250 \mathrm{~K}$ at $550 \mathrm{~m}$ and $242 \mathrm{~K}$ at $2000 \mathrm{~m})$, a minimum on January $29(243 \mathrm{~K}$ at $550 \mathrm{~m}$ and $238 \mathrm{~K}$ at $2000 \mathrm{~m})$, and a strong bump on January $30(250 \mathrm{~K}$ at $550 \mathrm{~m}$ and $242 \mathrm{~K}$ at $2000 \mathrm{~m}$ ) followed by a slow warming of the atmosphere after January 31 . The comparisons with the radiosondes tend to be better at $550 \mathrm{~m}$ above surface than at $2000 \mathrm{~m}$ above surface where a slight positive bias of $1-2 \mathrm{~K}$ is observed in the radiosonde data set compared with HAMSTRAD. At both layers, the IASI data sets are consistent with radiosondes and HAMSTRAD but with an obvious positive

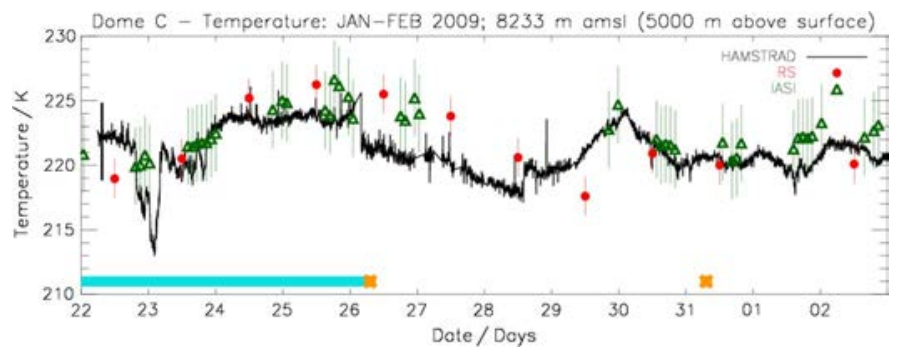

Fig. 15. As in Fig. 13, but for (black line) HAMSTRAD, (red filled circles) the radiosondes, and (green thick triangles) IASI at the altitude of $5000 \mathrm{~m}$ above surface from January 22 to February 2, 2009.

bias of $2-5 \mathrm{~K}$ at $550 \mathrm{~m}$ above surface reduced to $1-3 \mathrm{~K}$ at $2000 \mathrm{~m}$ above surface.

The time evolution of temperature shows basically two regimes with temperatures (January 25-27 and 30) when air masses at 400 and $300 \mathrm{hPa}$ are originated from oceanic midlatitudes (see Fig. 6) and a pronounced minimum in temperature on January 29 at 00:00 UTC when air masses at 400 and $300 \mathrm{hPa}$ mainly come from the Antarctic continent. It is interesting to note that, in addition to the good comparisons with radiosondes, the HAMSTRAD temperature time-series at 550 and $2000 \mathrm{~m}$ above surface are strongly correlated. Remember that, for $\mathrm{H}_{2} \mathrm{O}$ (previous section), the 550-m time evolution was correlated with the 50-m time series. Keeping in mind that the top height of the PBL is in average at $200 \mathrm{~m}$ above surface at Dome C in January-February ([2] and [14]), this means that the 550-m level is actually in the free troposphere. Thus, we should expect temperature at $550 \mathrm{~m}$ above surface to be correlated with temperature at $2000 \mathrm{~m}$ above surface, even considering a vertical resolution of $50 \mathrm{~m}$ (see Appendix). Regarding $\mathrm{H}_{2} \mathrm{O}$, it could be that the vertical resolution of the measurements expected to be $\sim 100 \mathrm{~m}$ in the free troposphere is much worse $(\sim 200-300 \mathrm{~m})$. Finally, note that the change from blue to white foam on January 26 has not impacted the retrieval of temperature at $2000 \mathrm{~m}$ above surface. The major reboot on January 26 cannot be incriminated since the reboot on January 31 has not produced any change in temperature.

3) Tropopause: As already explained in Section III-C3, the altitude of $5000 \mathrm{~m}$ above surface $(\sim 8 \mathrm{~km}$ amsl) is representative of the tropopause region (see Fig. 12). The temporal evolution of temperature as measured by HAMSTRAD, radiosondes, and IASI at 5000-m altitude is presented in Fig. 15. With the exception of the strong dip on January 23 around 00:00 UTC and two slight peaks on January 26 (foam change and major reboot) and on January 28 around 12:00 UTC (no recorded information), the general evolution of temperature from HAMSTRAD shows an increase from January 23 to 26 at 00:00 UTC (from 220 to $223 \mathrm{~K})$, a decrease until January $28(218 \mathrm{~K})$, an increase on January $30(223 \mathrm{~K})$, and a stabilization until the end of the period $(220 \mathrm{~K})$. Considering the radiosonde data set, this general evolution is observed with an atmosphere warmer from January 25 to 28 than the period January 29-February 2 . On January 23,30 , and 31 , the $5000-\mathrm{m}$ level is representative of the tropopause (see Fig. 12), and the HAMSTRAD and radiosonde temperatures agree to within $1 \mathrm{~K}$. The general increase in temperature from January 23 to 26 at 00:00 UTC can be 
traced by the oceanic origin of air masses using the 5-day back trajectories (see Fig. 6) at $200 \mathrm{hPa}$ : from $\sim 55^{\circ} \mathrm{S}$ on January 23 to $\sim 45^{\circ} \mathrm{S}$ on January 26 in the sector $30^{\circ}-90^{\circ}$ E. From January 26 to 29 at 00:00 UTC, air masses at $200 \mathrm{hPa}$ are mainly originating from the vicinity or above the Antarctic continent explaining the net decrease in temperature. On January 30 at 00:00 UTC, air masses at $200 \mathrm{hPa}$ come from oceanic latitudes at $45^{\circ}-60^{\circ} \mathrm{S}$, explaining the observed rapid increase in temperature. After January 31, air masses are essentially originating from oceanic latitudes $\sim 55^{\circ}-60^{\circ} \mathrm{S}$ in the sector $0^{\circ}-60^{\circ} \mathrm{W}$ (not shown).

Some differences can be observed, mainly during the period January 25-29, where radiosondes detect an atmosphere warmer by $2-3 \mathrm{~K}$ than HAMSTRAD. The IASI data set is in good agreement with HAMSTRAD and perfectly shows the maximum of temperature on January 30 that is not detected by the radiosondes because of the sampling effect. The strong dip in temperature as measured by HAMSTRAD on January 23 is not reproduced by IASI and seems to be an artifact.

Although the vertical resolution in HAMSTRAD temperature is $\sim 500 \mathrm{~m}$ around the tropopause producing a systematic warm bias of less than $0.5 \mathrm{~K}$ (see Appendix), the HAMSTRAD radiometer is sensitive enough around the tropopause to detect any change in temperature greater than $1 \mathrm{~K}$. Note that for heights greater than $6 \mathrm{~km}$ above surface (not shown), the evolution of temperature as measured by HAMSTRAD shows the same pattern as at $5 \mathrm{~km}$ above surface, underlining that the instrument measurements are not sensitive in the lower stratosphere. Finally, note that, as at $2000 \mathrm{~m}$ above surface, the change from blue to white foam on January 26 has impacted the retrieval of temperature at $5000 \mathrm{~m}$ above surface. The major reboot on January 26 cannot be incriminated since the reboot on January 31 has not produced any change in temperature.

\section{Statistical Analysis}

Here, as for $\mathrm{H}_{2} \mathrm{O}$, we perform a statistical analysis of all the temperature fields measured by HAMSTRAD, radiosondes, IASI, and in situ sensors (PT100 LGGE and CEA and HAMSTRAD) considering means and standard deviations during the period January 22-February 2, 2009. Furthermore, we also calculate biases and linear Pearson correlation coefficients of radiosondes, IASI, and in situ sensor (PT100 LGGE and CEA and HAMSTRAD) measurements with respect to coincident HAMSTRAD measurements during the same period. Means, standard deviations, biases, and correlations are presented in Fig. 16.

First of all, the vertical distribution of temperature averaged over the 12-day period above Dome $\mathrm{C}$ consistently behaves in the PBL and the free troposphere, regardless of the data set considered, and strongly differs from HAMSTRAD around the tropopause and in the stratosphere (Fig. 16, top left and bottom left). In the PBL up to $1000 \mathrm{~m}$ above surface, HAMSTRAD, the radiosondes, the PT100 LGGE, and the in situ HAMSTRAD sensor agree to better than $0.5 \mathrm{~K}$. The IASI data set and the PT100 CEA sondes show a warmer atmosphere by 2-3 K, probably induced by the impact of the warming of the sondes in the absence of winds since they are not force ventilated. For
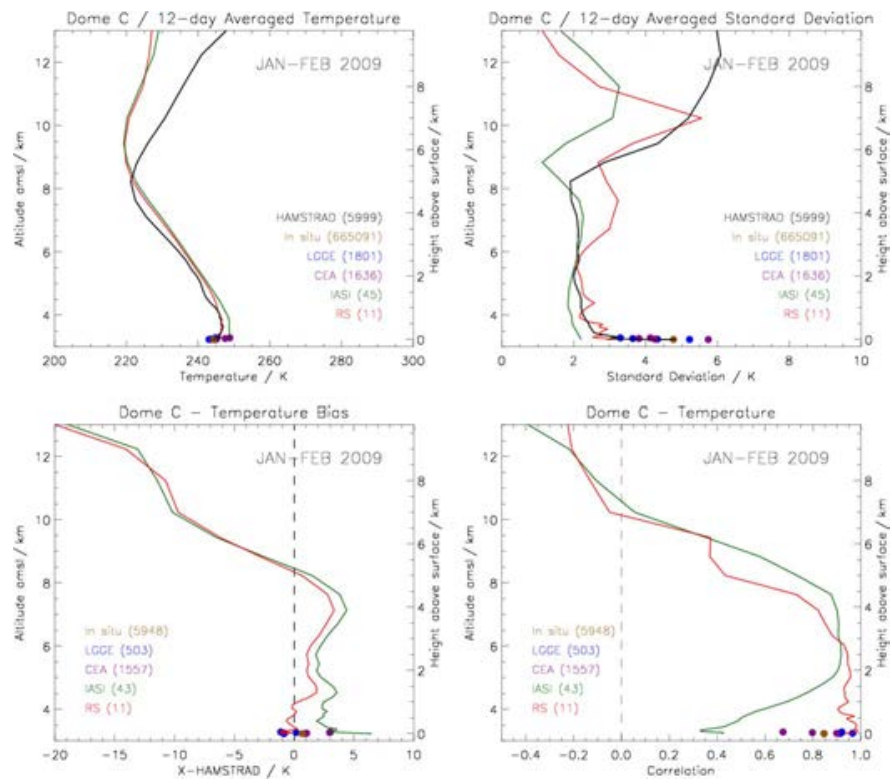

Fig. 16. (Top left) Vertical profiles of temperature (K) as measured by (black line) HAMSTRAD, (filled brown circles) in situ, (green line) IASI, (red line) the radiosondes, (filled blue circles) the LGGE PT100 sondes, and (filled purple circles) the CEA PT100 sondes above the altitude of the Dome-C station averaged from January 22 to February 2, 2009. (Top right) Same as top left except for the absolute standard deviation (K). (Bottom left) Same as top left except for the bias between all the data sets and HAMSTRAD (K). (Bottom right) Same as top left except for the correlation between all the data sets and HAMSTRAD. The number of profiles or points used in the averaging is noted in parentheses for each set of data. Moreover, note that bias and correlation versus HAMSTRAD are calculated in time coincidence explaining why the number of measurements used in the statistics is less than when calculating mean and standard deviation.

heights between 2000 and $5000 \mathrm{~m}$ above surface, HAMSTRAD has a cold bias of about 2-4 K compared with radiosondes and IASI, with IASI being warmer than the radiosondes by $1 \mathrm{~K}$. The tropopause as measured by HAMSTRAD is too low by $1-2 \mathrm{~km}$ and warmer by more than $10 \mathrm{~K}$ compared with radiosondes and IASI. The stratospheric temperature from HAMSTRAD strongly differs from radiosondes and IASI, but we have already noticed in the last section that the instrument has no sensitivity in this region.

The standard deviations calculated over the 12-day period (Fig. 16, top right) in the PBL (0-200 $\mathrm{m}$ above surface) from HAMSTRAD and in situ (PT100 LGGE and CEA and meteorological sensor from HAMSTRAD) data agree very well and tend to show the strong diurnal cycle in temperature (3-6 K) that is indeed absent in the IASI standard deviation and radiosonde databases $(2-3 \mathrm{~K})$ because they do not sample the entire diurnal cycle. From 200 to $3000 \mathrm{~m}$ above surface, radiosonde and HAMSTRAD standard deviations are in good agreement $(2-3 \mathrm{~K})$, whereas IASI standard deviation is slightly less (about $2 \mathrm{~K}$ ). From 3 to $5 \mathrm{~km}$ above surface, HAMSTRAD and IASI standard deviations are consistent with each other (about $2 \mathrm{~K}$ ), whereas the radiosonde standard deviation is greater $(\sim 3 \mathrm{~K})$. Above the tropopause ( $\sim 5 \mathrm{~km}$ above surface), the standard deviations from the three data sets are not consistent at all (no sensitivity of HAMSTRAD in this region).

Finally, the correlation between all the other data sets and HAMSTRAD in temporal coincidence (Fig. 16, bottom right) 
is very instructive. For heights less than $4 \mathrm{~km}$ above surface, radiosonde and HAMSTRAD data sets are very well correlated to better than 0.8 , being close to 1 at the surface. The in situ data (PT100 LGGE and HAMSTRAD meteorological sensor) are also well correlated with HAMSTRAD (0.85-0.95), showing the strong sensitivity of HAMSTRAD to sound the PBL and to detect the strong diurnal cycle in temperature. IASI is weakly correlated with HAMSTRAD in the lowermost troposphere (0.4), probably due to the weak sensitivity of IASI in the PBL induced by its poor vertical resolution of $\sim 1 \mathrm{~km}$ (see Table II), but the correlation is better from 2 to $5 \mathrm{~km}$ above surface (0.9). The in situ PT100 CEA sensors are not so well correlated with HAMSTRAD (0.65-0.90), probably because the sondes were not force ventilated and did warm in the absence of winds for some periods. Above the tropopause, the correlation of IASI and radiosondes with HAMSTRAD is rather low $(<0.5)$ because HAMSTRAD has no sensitivity.

In conclusion, the measurements of temperature from HAMSTRAD at Dome $\mathrm{C}$ tend to cover a wide vertical range from the surface to about 4-6 km above surface, namely, from the PBL to the tropopause. HAMSTRAD temperature measurements have a high sensitivity in the PBL and in the free troposphere and, to a lesser extent, only limited sensitivity around the tropopause, which is sounded $2 \mathrm{~km}$ too low compared with radiosondes. The temporal evolution of temperature is, in general, well represented by HAMSTRAD at all levels within the limits of the measurement noise, a consequence of the instrument's good temporal sampling capability.

\section{Conclusions}

The HAMSTRAD instrument has been successfully deployed outdoors at Dome C (Concordia Station), Antarctica, during its first summertime campaign for 12 days from January 22 to February 2, 2009. The microwave radiometer operating at $183 \mathrm{GHz}\left(\mathrm{H}_{2} \mathrm{O}\right.$ line $)$ and $60 \mathrm{GHz}\left(\mathrm{O}_{2}\right.$ line to retrieve temperature) measured IWV, absolute humidity and temperature profiles from the surface to about $6 \mathrm{~km}$ above surface of the Dome-C station ( $\sim 9 \mathrm{~km}$ amsl) with a temporal resolution of $7 \mathrm{~min}$. While the shelter was not ready for hosting the instrument, and liquid nitrogen was not used at the station for calibrating spectra, measurements of temperature and humidity were nevertheless scientifically exploitable. They have been compared against radiosondes launched at the station at 12:00 UTC, in situ PT100, and Humicap sondes from two French laboratories (LGGE and CEA) installed along the vertical extent of a 45-m tower, an in situ meteorological sensor attached to the HAMSTRAD instrument, and the IASI spaceborne instrument.

The variability of IWV observed by HAMSTRAD with extremely low values of $0.5 \mathrm{~kg} \cdot \mathrm{m}^{-2}$ was also detected in the radiosonde data with a very high correlation of 0.98 . IASI cloud-free measurements of IWV did not reproduce the HAMSTRAD IWV variations (weak correlation of 0.58). In general, the measurements of absolute humidity from HAMSTRAD at Dome $\mathrm{C}$ tend to cover a wide vertical range from the surface to about 6-km altitude, namely, from the PBL to the tropopause, with a high sensitivity in the free troposphere. The strong diurnal variation of $\mathrm{H}_{2} \mathrm{O}$ observed by the in situ sensors in the PBL is not very well detected by the radiometer, but in the free troposphere, the correlation of HAMSTRAD with radiosondes can reach 0.8-0.9. Around the tropopause, the HAMSTRAD data set is consistent with the IASI and the radiosonde data sets but with a dry bias of about $0.01 \mathrm{~g} \cdot \mathrm{m}^{-3}$.

Compared with radiosondes, HAMSTRAD tends to show a wetter atmosphere by $\sim 0.5 \mathrm{~g} \cdot \mathrm{m}^{-3}$ close to the surface, by $0.1-0.3 \mathrm{~g} \cdot \mathrm{m}^{-3}$ below $2-\mathrm{km}$ altitude, and a drier atmosphere above by $\sim 0.1 \mathrm{~g} \cdot \mathrm{m}^{-3}$. This systematic effect cannot be attributed to the vertical resolution of the $\mathrm{H}_{2} \mathrm{O}$ measurements (from 30 to $50 \mathrm{~m}$ in the PBL to $500 \mathrm{~m}$ around the tropopause). We also pointed out that the instrument and, more precisely, the humidity channel at $183 \mathrm{GHz}$ was rather sensitive to blackouts (major power failures) at the station. This phenomenon observed during the first 2009 summer campaign also occurred during the second 2010 summer campaign. We noticed that a systematic reboot of the radiometer's data acquisition system after a blackout forced HAMSTRAD to nominally operate and produced $\mathrm{H}_{2} \mathrm{O}$ profiles very consistent with radiosondes. This might be caused by an instability of the noise diode attached to the $183-\mathrm{GHz}$ channels, enabling the automated calibration every minute.

Temperature profiles can be measured using two modes of observation: boundary layer (low elevation observations) and full troposphere (higher elevation observations). Combining these two modes yields vertical profiles of temperature very sensitive in the PBL and in the free troposphere, degrading around the tropopause. The strong diurnal signal measured around the surface by HAMSTRAD $(3-6 \mathrm{~K})$ is very consistent with all the other in situ data sets. The temporal evolution over the 12-day period in the PBL is also consistent with all the other data sets (radiosondes, IASI, in situ sondes, and meteorological sensors), and in the free troposphere and around the tropopause with radiosondes and IASI; although, some dry biases are present with IASI. For heights less than $4 \mathrm{~km}$ above surface, HAMSTRAD correlates very well with radiosondes and in situ sensors (correlation better than 0.8 ) but less with IASI (0.4). Below the tropopause ( $\sim 5 \mathrm{~km}$ above surface, $\sim 8 \mathrm{~km}$ amsl), IASI and HAMSTRAD correlation reaches 0.9 , whereas in the lower stratosphere, the correlation of IASI and radiosondes with HAMSTRAD is rather low $(<0.5)$, but the instrument loses sensitivity in this region.

Throughout the 12-day period (except on January 23), in the lowermost troposphere (from the surface up to $500 \mathrm{~m}$ above surface), the HAMSTRAD temperature profiles mimic the profiles measured by the radiosondes. From $500 \mathrm{~m}$ up to $5 \mathrm{~km}$ above surface (around the tropopause), the HAMSTRAD temperature profile has a cold bias from 1 to $5 \mathrm{~K}$ compared with the radiosondes, but for some dates (e.g., January 25 and 29), the HAMSTRAD temperature is very close to the radiosonde temperature. HAMSTRAD generally measures a tropopause lower by about $1-2 \mathrm{~km}$ and warmer than the radiosondes except on some occasions, as on January 23, 30, and 31. In the stratosphere, the HAMSTRAD profile is insensitive to the real atmosphere. As for $\mathrm{H}_{2} \mathrm{O}$, these systematic biases cannot be attributed to the vertical resolution of the temperature 
measurements (from $\sim 10 \mathrm{~m}$ in the PBL to $\sim 500 \mathrm{~m}$ around the tropopause).

These results obtained during the first 12-day long summer campaign in 2009 are being confirmed during the second summer campaign that started in January 2010. A detailed analysis of the diurnal variations of $\mathrm{H}_{2} \mathrm{O}$ and temperature in the PBL has been performed using HAMSTRAD measurements from January to June 2010 [14]. A comprehensive analysis of all the measurements performed by HAMSTRAD in 2010 along the vertical is actually being performed ([23] and [24]). The instrument is now inserted in its shelter and measures $\mathrm{H}_{2} \mathrm{O}$ and temperature continuously. Finally, the HAMSTRAD measurements of temperature and $\mathrm{H}_{2} \mathrm{O}$ are presently used for improving the retrievals of satellite IR measurements such as IASI that seem to be strongly affected by erroneous surface parameters over the Antarctic Plateau through the CONCORDIASI campaign held in spring 2010 [36].

\section{APPENDIX \\ VERTICAL RESOLUTION}

Optimal Estimation Method: To compute the vertical resolution of the $\mathrm{H}_{2} \mathrm{O}$ and temperature measurements from HAMSTRAD, we have used the generic Microwave Odin LIne Estimation and REtrieval (MOLIERE) radiative transfer and inversion tool. The MOLIERE code [37] was initially developed for the Odin satellite [38] and used in different groundbased projects, e.g., $\mathrm{H}_{2} \mathrm{O}$ at $22 \mathrm{GHz}$ [39], $\mathrm{O}_{3}$ at $110 \mathrm{GHz}$ [40], and $\mathrm{ClO}$ at $278 \mathrm{GHz}$ [41]. The MOLIERE code is separated into a forward model and a retrieval code. The forward model includes modules for spectroscopy, radiative transfer, and sensor characteristics: antenna shape, sideband filter (single side band at $60 \mathrm{GHz}$ and double side band at $183 \mathrm{GHz}$ ), filter banks, elevation angles. Spectroscopic line parameters for the line-by-line calculations have been taken from the Verdandi database (http://www.rss.chalmers.se/gem/Research/ verdandi.html), which merges frequencies, line intensities, and lower state energies from the JPL catalogue [42] with pressure broadening parameters from the HITRAN compilation [43]. Only the $\mathrm{O}_{2}$ and $\mathrm{H}_{2} \mathrm{O}$ transitions around 60 and $183 \mathrm{GHz}$ were considered, respectively.

The retrieval code is based upon the optimal estimation method (OEM) [44] and, coupled with the forward model, allows nonlinear retrievals based on a Newton LevenbergMarquardt iteration scheme. In this paper, the a priori information on $\mathrm{H}_{2} \mathrm{O}$, temperature, pressure, and altitude has been taken from the European Center for Medium-Range Weather Forecasts analysis. The a priori error on $\mathrm{H}_{2} \mathrm{O}$ and temperature profiles has been set to $75 \%$ of the a priori mixing ratios and $10 \mathrm{~K}$ for the a priori temperature profile, respectively, and a diagonal covariance matrix has been built. The maximum number of iterations has been set to 1 since the real atmosphere and the a priori atmosphere were considered as similar to get the optimal results in terms of vertical resolutions. The retrieval vertical grid has been nominally designed to match the expected vertical resolution of the measurements: steps from 30 to $100 \mathrm{~m}$ from the surface to $1 \mathrm{~km}$ above surface, steps from 100 to $400 \mathrm{~m}$ from 1 to $10 \mathrm{~km}$ above surface, and steps from $500 \mathrm{~m}$
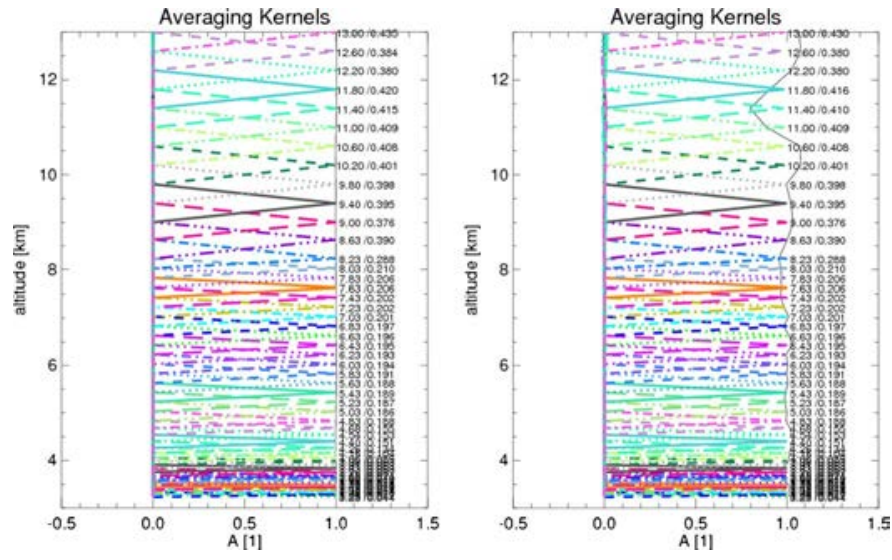

Fig. 17. Averaging kernels of (left) temperature and (right) $\mathrm{H}_{2} \mathrm{O}$ relative to the HAMSTRAD measurements at Dome $C$ from 3 to $13 \mathrm{~km}$ amsl $(0-10 \mathrm{~km}$ above surface). The two sets of figures in the extreme right of each figure show, for each considered averaging kernel, 1) the altitude of the peak and 2) the vertical resolution (namely, the width at half-maximum) in kilometers. All the averaging kernels calculated in the study are presented in the figure, considering steps from 30 to $100 \mathrm{~m}$ from the surface to $1 \mathrm{~km}$ above surface, steps from 100 to $400 \mathrm{~m}$ from 1 to $10 \mathrm{~km}$ above surface, and steps from $500 \mathrm{~m}$ to $5 \mathrm{~km}$ from 10 to $70 \mathrm{~km}$ above surface.
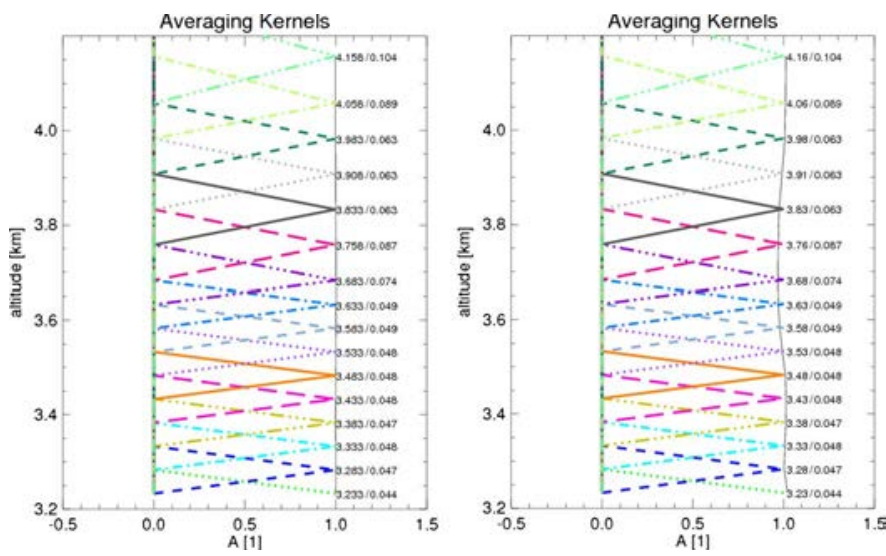

Fig. 18. Same as in Fig. 17, but from 3.2 to $4.2 \mathrm{~km}$ amsl $(0-1 \mathrm{~km}$ above surface).

to $5 \mathrm{~km}$ from 10 to $70 \mathrm{~km}$ above surface. The scanning angles have been set to 20 , varying from $1^{\circ}$ elevation to zenith with a high angular resolution at low elevation.

The width at half-maximum of the averaging kernels provided by the optimal estimation theory can be considered as representative of the vertical resolution of the measurements. The sum of the elements of each averaging kernel (the measurement response) is an indication of the information provided by the measurement upon the a priori information. The optimal vertical domain where meaningful information can be retrieved is estimated by a measurement response greater than 0.75 , which means that the a priori information contaminates the retrieval by less than $25 \%$.

The averaging kernels for temperature and $\mathrm{H}_{2} \mathrm{O}$ measurements from HAMSTRAD are presented in Figs. 17-19 when considering the atmosphere $0-10 \mathrm{~km}, 0-1 \mathrm{~km}$, and 0-80 km above surface, respectively, over the whole HAMSTRAD standard retrieval range; over the lowermost troposphere; and, as a prospective analysis, over the entire troposphere and stratosphere, respectively. First of all, we can note that, in 

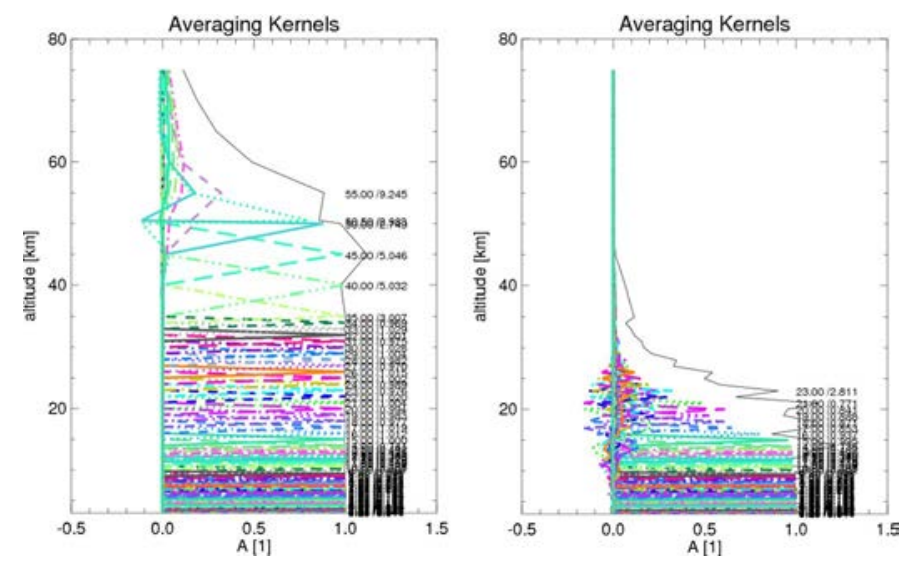

Fig. 19. Same as in Fig. 17, but from 3 to $80 \mathrm{~km}$ amsl $(0-80 \mathrm{~km}$ above surface).

this optimum configuration, measurements of HAMSTRAD indeed cover the entire troposphere with better sensitivity in the lowermost troposphere compared with the upper troposphere with a resolution of 40-50 m close to the surface, degrading to $\sim 100 \mathrm{~m}$ at $1 \mathrm{~km}$ above surface, reaching $400-500 \mathrm{~m}$ at $10 \mathrm{~km}$ above surface. It is worth mentioning that the sensitivity of the $\mathrm{H}_{2} \mathrm{O}$ measurements drops when reaching $12-13 \mathrm{~km}$ above surface, whereas the sensitivity of the temperature measurements decreases at altitudes above $30-35 \mathrm{~km}$ with a vertical resolution of $\sim 3-5 \mathrm{~km}$.

Correlation Method: From a theoretical point of view, the vertical resolutions $\left(\Delta_{1 / 2}\right)$ of the HAMSTRAD $\mathrm{H}_{2} \mathrm{O}$ and temperature measurements were expected to be 100 and $50 \mathrm{~m}$, respectively [21]. Considering a detailed analysis of the measurements performed in the PBL from January to June 2010 [14], we refined these two figures and found that, in the lowermost troposphere, the vertical resolutions of the HAMSTRAD measurements of $\mathrm{H}_{2} \mathrm{O}$ and temperature were improved to $\sim 10-20 \mathrm{~m}$ and $\sim 25-30 \mathrm{~m}$, respectively. Here, we use to same methodology as in [14] to evaluate $\left(\Delta_{1 / 2}\right)$ for $\mathrm{H}_{2} \mathrm{O}$ and temperature from the surface to $10 \mathrm{~km}$ above surface $(\sim 13 \mathrm{~km}$ amsl) using the measurements performed during the 12-day period of 2009.

We have considered in Fig. 20 the temperature-temperature correlation versus height (top) and the $\mathrm{H}_{2} \mathrm{O}-\mathrm{H}_{2} \mathrm{O}$ correlation versus height (bottom) of the HAMSTRAD data over the 12-day period of 2009. This represents the linear Pearson correlation between the temperature and $\mathrm{H}_{2} \mathrm{O}$ time series at two different heights. If we suppose a well-mixed atmosphere or an atmosphere uniformly varying with respect to time along the vertical, the off-diagonal terms of the correlation matrix will be close to unity whatever the height and whatever the vertical resolution considered. If we now suppose an atmosphere that does not uniformly vary along the vertical (e.g., with an obvious transition between the PBL and the free atmosphere at an altitude $h_{2}$ ), the off-diagonal terms will thus depart from unity and will reach a value of 0.8 at an altitude $h_{2}^{\prime}$. We arbitrarily consider that two terms are no longer correlated when their correlation rate is below the value of 0.8 . Note that using a value ranging from 0.7 to 0.9 as a threshold does not significantly change our conclusions. The vertical resolution of the measurements $\Delta_{1 / 2}$ can be estimated by the minimum reached by the quantity $\Delta_{1 / 2}=\left|h_{2}-h_{2}^{\prime}\right|$.

If we first consider the domain containing the PBL, namely, 0-200 $\mathrm{m}$ above surface (middle panels in Fig. 20), in the temperature data set, for $h_{2}=20 \mathrm{~m}$, we can find $h_{2}^{\prime}=50 \mathrm{~m}$, and in the $\mathrm{H}_{2} \mathrm{O}$ data set, for $h_{2}=50 \mathrm{~m}$, we can find $h_{2}^{\prime}=$ $100 \mathrm{~m}$. Thus, the vertical resolution $\Delta_{1 / 2}$ of the HAMSTRAD temperature and $\mathrm{H}_{2} \mathrm{O}$ measurements below $200 \mathrm{~m}$ can be estimated to be $\Delta_{1 / 2}=30$ and $50 \mathrm{~m}$, respectively. These figures are rather consistent with the resolutions estimated from the 2010 data and with the OEM study (previous section).

Now, if we consider the free troposphere, namely, $1-4 \mathrm{~km}$ above surface (right panels in Fig. 20), in the temperature data set, for $h_{2}=1.9 \mathrm{~km}$, we can find $h_{2}^{\prime}=2.4 \mathrm{~km}$, and in the $\mathrm{H}_{2} \mathrm{O}$ data set, for $h_{2}=2.5 \mathrm{~km}$, we can find $h_{2}^{\prime}=$ $3.1 \mathrm{~km}$. Thus, the vertical resolution $\Delta_{1 / 2}$ of the HAMSTRAD temperature and $\mathrm{H}_{2} \mathrm{O}$ measurements for heights greater than $200 \mathrm{~m}$ above surface can be estimated to be $\Delta_{1 / 2}=500$ and $600 \mathrm{~m}$, respectively. These figures, somehow much greater than the initial values estimated prior to the construction of the instrument, can be considered as an upper limit for the vertical resolutions and will be updated considering the entire 2010 data set [23], [24]. Our correlation study together with the interpretation of the evolution of the data set in the free troposphere (Sections III-C and IV-B) tend to show that the vertical resolution in temperature is much better than the vertical resolution in $\mathrm{H}_{2} \mathrm{O}$, although this study also depends on the natural variability of the considered data set. Nevertheless, in Fig. 20 and for heights greater than $3 \mathrm{~km}$ above surface, the $\mathrm{H}_{2} \mathrm{O}$ resolution appears to be better than the temperature resolution, but both $\mathrm{H}_{2} \mathrm{O}$ amounts and HAMSTRAD $\mathrm{H}_{2} \mathrm{O}$ measurement sensitivity start obviously decreasing. In the vicinity of the tropopause ( $\sim 6 \mathrm{~km}$ above surface), it is rather difficult to draw any conclusions from our study because of 1) a very limited data set available in 2009 and 2) a loss of sensitivity in the measurements of both $\mathrm{H}_{2} \mathrm{O}$ and temperature.

The results obtained with the correlation method (CM) are very consistent with the OEM results presented before, with a resolution in the OEM less than in the CM in the lowermost troposphere and, conversely, in the mid-troposphere to upper troposphere. The CM can be also used to assess more physical details in the temporal evolution of the atmosphere above Dome C. First, considering Fig. 20, the largest temperature fluctuations are found to be located around $\sim 30 \mathrm{~m}, \sim 2.2 \mathrm{~km}$, and $\sim 5 \mathrm{~km}$, corresponding to the height of the surface-based inversions, height of synoptic winds, and tropopause height, respectively. Second, we can notice an obvious anticorrelation $(\sim-0.9)$ between the temperature evolution in the PBL and around the tropopause. The anticorrelation is also present when considering the whole 2010 data sets including HAMSTRAD, radiosonde, IASI, and ECMWF (not shown). This can be attributed to 1) the origin of air masses reaching Dome $\mathrm{C}$ (either from the Antarctic continent or from the surrounding oceans) and 2) the horizontal distribution of temperature, depending on the month and the pressure surface considered (see [23]).

Impact of Vertical Resolution on Vertical Profiles: Since the analysis of the temporal evolution of $\mathrm{H}_{2} \mathrm{O}$ and temperature over 

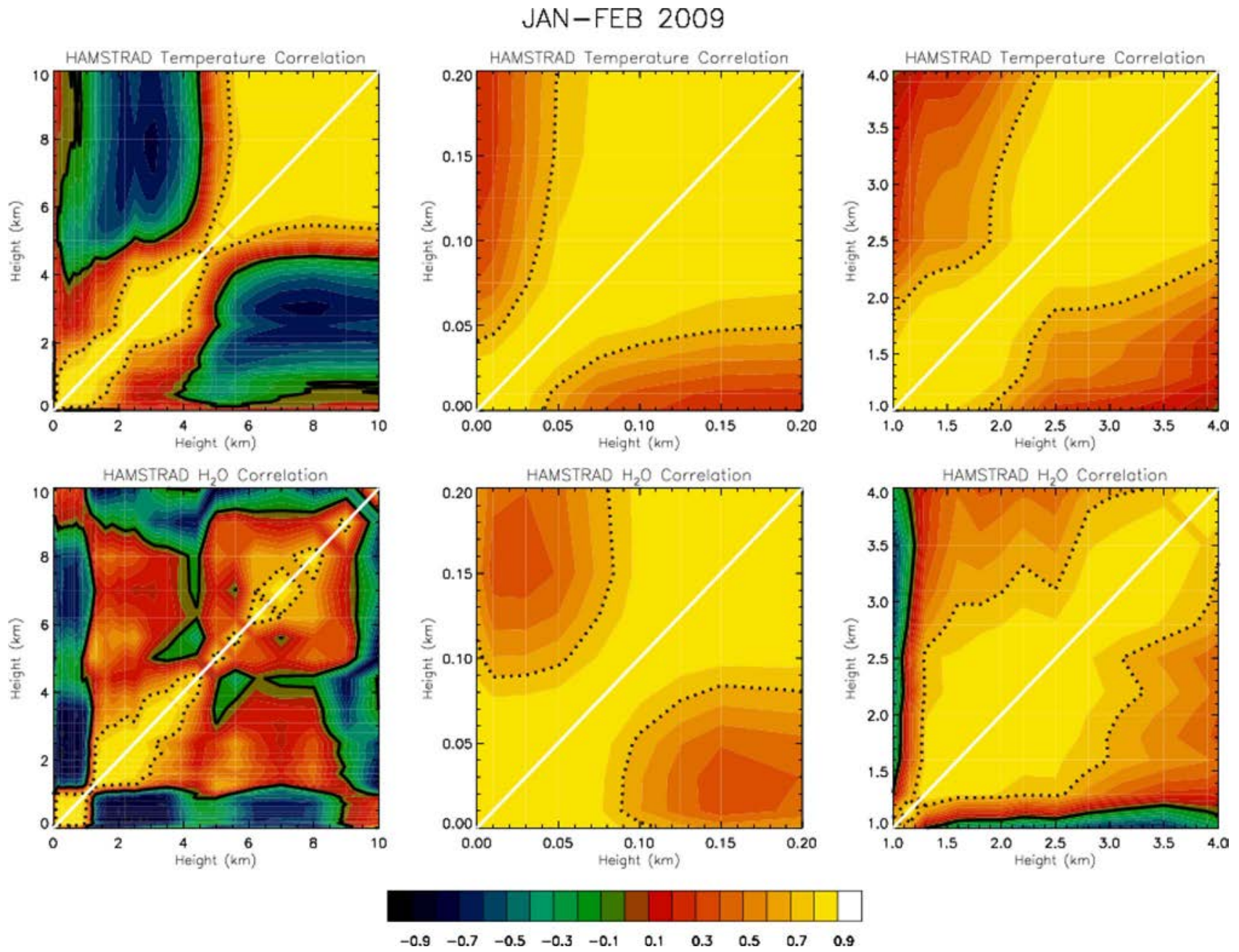

Fig. 20. (Top) Correlation between diurnal temperature time series at two different heights (represented on the two axes of the diagrams) from HAMSTRAD data in January-February 2009 (left) from 0 to $10 \mathrm{~km}$, (center) from 0 to $0.2 \mathrm{~km}$, and (right) from 1 to $4 \mathrm{~km}$. (Bottom) Same as top but for absolute humidity. The black solid line represents a correlation of 0 , whereas the black dotted line represents a correlation of 0.80 . The white line represents the diagonal terms.

Dome $\mathrm{C}$ presented in this paper is based upon remote sensing data sets with different vertical resolutions (HAMSTRAD and IASI), we try now to estimate the impact of these resolutions on the vertical profiles. To do this, we have considered the highresolution vertical profiles of radiosondes to be the "truth" and applied a unitary triangular function centered at a height of $h_{0}$ with a vertical resolution (width at half-maximum) of $\Delta_{1 / 2}$. Figs. 21 and 22 show the convolution of the triangular functions on the 12-day average profiles of $\mathrm{H}_{2} \mathrm{O}$ and temperature, respectively, considering different resolutions: $\Delta_{1 / 2}=30,50,500$, 1000,1500 , and $2000 \mathrm{~m}$. Note that $\Delta_{1 / 2}=30,50$, and $500 \mathrm{~m}$ are related to the HAMSTRAD resolutions, whereas $\Delta_{1 / 2}=$ 1000,1500 , and $200 \mathrm{~m}$ are related to the IASI resolutions.

For $\mathrm{H}_{2} \mathrm{O}$ (see Fig. 21), in the PBL (0-200 $\mathrm{m}$ above surface), a poor resolution tends to increase the amount of $\mathrm{H}_{2} \mathrm{O}$ by $2 \%-30 \%$ when $\Delta_{1 / 2}$ is greater than $500 \mathrm{~m}$ since, over Dome $\mathrm{C}$, the $\mathrm{H}_{2} \mathrm{O}$ gradient is positive over this domain. From 200 to $1500 \mathrm{~m}$ above surface, the poor-resolution profiles are smaller than the high-resolution profile by $2 \%-20 \%$, degrading as $\Delta_{1 / 2}$ varies from 500 to $2000 \mathrm{~m}$. For heights greater than $1500 \mathrm{~m}$ above surface, the poor-resolution profiles are systematically greater than the high-resolution profiles by about $10 \%-20 \%$ in the free troposphere, reaching $10 \%-70 \%$ in the upper troposphere/lower stratosphere as $\Delta_{1 / 2}$ varies from 50 to $2000 \mathrm{~m}$. Note that a resolution $\Delta_{1 / 2}$ less than $50 \mathrm{~m}$ does not significantly impact the $\mathrm{H}_{2} \mathrm{O}$ amounts compared with highresolution profiles.

For temperature (see Fig. 22), in the PBL (0-200 m above surface), a poor resolution tends to significantly warm the atmosphere by $2 \mathrm{~K}$ to almost $7 \mathrm{~K}$ when $\Delta_{1 / 2}$ varies from 50 to $2000 \mathrm{~m}$ since, over Dome $\mathrm{C}$, the temperature gradient is positive over this domain. The steepness of the temperature gradient is even greater during the winter season, and the impact of the vertical resolution on temperature close to the surface is expected and has been measured to be even larger [14]. From 200 to $3500 \mathrm{~m}$ above surface, the poor-resolution profiles are less than the high-resolution profile by $0.2 \mathrm{~K}$ to a maximum of $2 \mathrm{~K}$, degrading as $\Delta_{1 / 2}$ varies from 500 to $2000 \mathrm{~m}$. For heights between 3500 and $7500 \mathrm{~m}$ above surface, the poorresolution profiles are systematically greater than the highresolution profiles by about $0.2-2 \mathrm{~K}$ as $\Delta_{1 / 2}$ varies from 500 to $2000 \mathrm{~m}$. For heights greater than $7500 \mathrm{~m}$ above surface, in the lower stratosphere, the poor-resolution profiles are less than the high-resolution profile by $0.2-0.5 \mathrm{~K}$ as $\Delta_{1 / 2}$ varies from 500 to $2000 \mathrm{~m}$. Finally, note that 1) contrarily to $\mathrm{H}_{2} \mathrm{O}$, a resolution $\Delta_{1 / 2}$ of $50 \mathrm{~m}$ can significantly impact surface temperature 

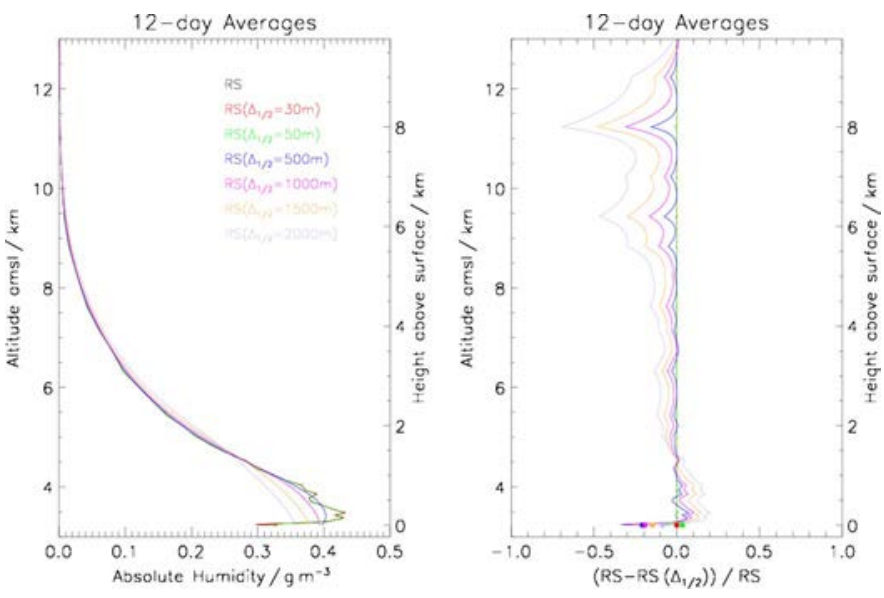

Fig. 21. (Left) Vertical profiles of the absolute humidity as measured by the radiosondes at 12:00 UT averaged over the 12-day period of 2009 at Dome C (black line), and convolved with a triangular function of vertical resolution (width at half-maximum) $\Delta_{1 / 2}=$ (red line) $30 \mathrm{~m}$, (green line) $50 \mathrm{~m}$, (blue line) $500 \mathrm{~m}$, (pink line) $1000 \mathrm{~m}$, (orange line) $1500 \mathrm{~m}$, and (lavender line) $2000 \mathrm{~m}$. (Right) Vertical profiles of the relative difference between the absolute humidity as measured by the radiosondes at 12:00 UT on February 2, 2009 at Dome C (black line), and radiosonde profile convolved with a triangular function of vertical resolution (width at half-maximum) $\Delta_{1 / 2}=$ (red line) $30 \mathrm{~m}$, (green line) $50 \mathrm{~m}$, (blue line) $500 \mathrm{~m}$, (pink line) $1000 \mathrm{~m}$, (orange line) $1500 \mathrm{~m}$, and (lavender line) $2000 \mathrm{~m}$.
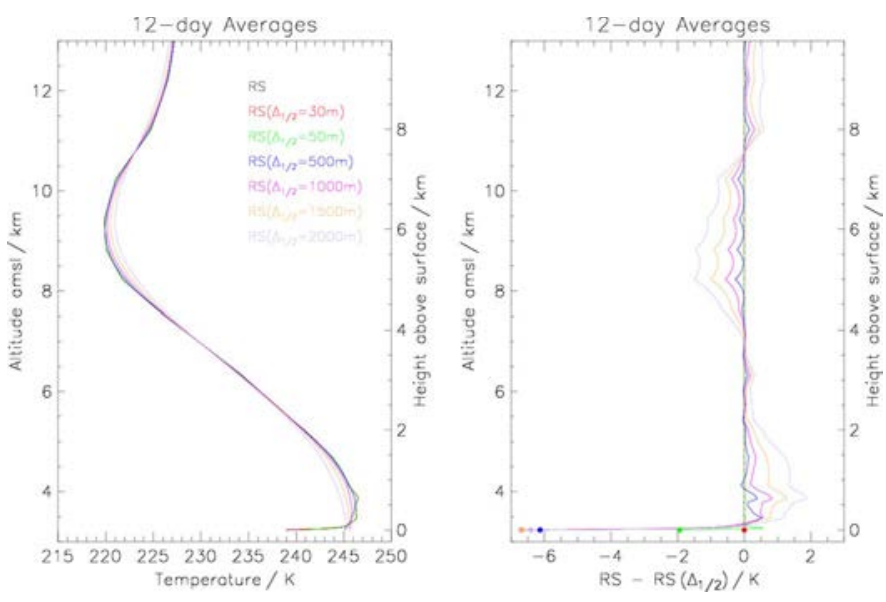

Fig. 22. Same as in Fig. 21 but for temperature, except that, on the right, absolute differences $(\mathrm{K})$ are represented.

compared with high-resolution profiles, and 2) the tropopause height remains roughly the same in all investigated cases. The results presented here are indeed entirely dependent on the shape and on the intensity of the vertical profiles of temperature and $\mathrm{H}_{2} \mathrm{O}$. Thus, the biases estimated with this method may vary depending on the season and on the local time of the considered period.

\section{ACKNOWLEDGMENT}

The authors would like to thank all the French and Italian staff (technicians, engineers, and scientists) who have worked at the Concordia Base over the first (2009) and second (2010) summertime campaigns and the Institute Paul-Emile Victor (IPEV) staff for doing their best in taking care of the logistics of the missions and the Australian Antarctic Division staff for the Australian logistics in 2009. IASI has been developed and built under the responsibility of the Centre National d'Etudes Spatiales (CNES). It is flown onboard the MetOp satellites as part of the EUMETSAT Polar System. The IASI L2 data are received through the EUMETCast NRT data distribution service. IASI vertical profiles of water vapor and temperature were extracted from the Ether French atmospheric database (http://ether.ipsl.jussieu.fr). They would also like to thank the British Atmospheric Data Centre (BADC), which is part of the NERC National Centre for Atmospheric Science (NCAS), for the use of its calculated trajectory data; the European Centre for Medium-Range Weather Forecasts that supplied the initial data via the BADC; and B. Plazolles for calculating averaging kernels adapted to the HAMSTRAD measurements. Finally, they would like to thank the three anonymous reviewers for their very helpful comments.

\section{REFERENCES}

[1] J. Turner, T. A. Lachlan-Cope, S. Colwell, G. J. Marshall, and W. M. Connolley, "Significant warming of the Antarctic winter troposphere," Science, vol. 311, no. 5769, pp. 1914-1917, Mar. 2006.

[2] S. Argentini, A. Viola, A. M. Sempreviva, and I. Petenko, "Summer boundary-layer height at the plateau site of Dome C, Antarctica," Bound. Layer Meteorol., vol. 115, no. 3, pp. 409-422, Jun. 2005.

[3] G. P. Brasseur, J. J. Orlando, and G. S. Tyndall, Atmospheric Chemistry and Global Change., 2nd ed. New York: Oxford Univ. Press, 1999.

[4] K. M. Hines, D. H. Bromwich, P. J. Rasch, and M. J. Iacono, "Antarctic clouds and radiation within the NCAR climate models," J. Clim., vol. 17, no. 6, pp. 1198-1212, Mar. 2004.

[5] M. S. Town and V. P. Walden, "The surface energy budget and behavior of the stable boundary layer over the South Pole," J. Geophys. Res., vol. 114, pp. D22107-1-D22107-15, Nov. 2009.

[6] E. Aristidi, K. Agabi, M. Azouit, E. Fossat, J. Vernin, T. Travouillon, J. S. Lawrence, C. Meyer, J. W. V. Storey, B. Halter, W. L. Roth, and V. Walden, "An analysis of temperatures and wind speeds above Dome C, Antarctica," Astron. Astrophys., vol. 430, no. 2, pp. 739-746, Feb. 2005.

[7] P. S. Anderson and W. D. Neff, "Boundary layer physics over snow and ice," Atmos. Chem. Phys., vol. 8, no. 13, pp. 3563-3582, 2008.

[8] D. Davis, J. B. Nowak, G. Chen, M. Buhr, R. Arimoto, A. Hogan, F. Eisele, L. Mauldin, D. Tanner, R. Shetter, B. Lefer, and P. McMurry, "Unexpected high levels of NO observed at South Pole," Geophys. Res. Lett., vol. 28, no. 19, pp. 3625-3628, 2001.

[9] A. E. Jones, R. Weller, P. S. Andreson, H. W. Jacobi, E. W. Wolff, O. Schrems, and H. Miller, "Measurements of NOx emissions from the Antarctic snowpack," Geophys. Res. Lett., vol. 28, no. 8, pp. 1499-1502, Apr. 2001.

[10] E. Aristidi, A. Agabi, J. Vernin, M. Azouit, F. Martin, A. Ziad, and E. Fossat, "Antarctic site testing: First daytime seeing monitoring at Dome C," Astron. Astrophys., vol. 406, no. 1, pp. L19-L22, Jul. 2003.

[11] C. Tomasi, B. Petkov, E. Benedetti, V. Vitale, A. Pellegrini, G. Dargaud, L. De Silvestri, P. Grigioni, E. Fossat, W. L. Roth, and L. Valenziano, "Characterization of the atmospheric temperature and moisture conditions above Dome C (Antarctica) during austral summer and fall months," J. Geophys. Res., vol. 111, no. D20, pp. D20305-1- D20305-12, Oct. 2006.

[12] P. Tremblin, V. Minier, N. Schneider, G. A. Durand, M. C. B. Ashley, J. S. Lawrence, D. M. Luong-van, J. W. V. Storey, G. A. Durand, Y. Reinert, C. Veyssiere, C. Walter, P. Ade, P. G. Calisse, Z. Challita, E. Fossat, L. Sabbatini, A. Pellegrini, P. Ricaud, and J. Urban, "Site testing for submillimetre astronomy at Dome C in Antarctica," Astron. Astrophys., vol. 535, pp. A112-1-A112-8, Nov. 2011.

[13] P. Ricaud, S. Derrien, J.-P. Chaboureau, J.-L. Attié, T. Rose, H. Czekala, C. Genthon, L. Genoni, A. Pellegrini, and G. Durand, "The 183-GHz radiometer HAMSTRAD: First measurements of temperature and humidity in the PBL at Dome C (Antarctica)," in Proc. ISARS, Paris, France, Jun. 2010.

[14] P. Ricaud, C. Genthon, J.-L. Attié, F. Carminati, G. Canut, P. Durand, J.-F. Vanacker, L. Moggio, Y. Courcoux, A. Pellegrini, and T. Rose, "Summer to winter diurnal variabilities of temperature and water vapour 
in the surface atmosphere as observed by HAMSTRAD over Dome C, Antarctica," Bound. Layer Meteorol., vol. 143, no. 1, pp. 227-259, Apr. 2012.

[15] E. R. Westwater, S. Crewell, and C. Mätzler, "A review of surface-based microwave and millimeter-wave radiometric remote sensing of the troposphere," Radio Sci. Bull., vol. 3010, pp. 59-80, Sep. 2004.

[16] A. L. Pazmany, "A compact $183-\mathrm{GHz}$ radiometer for water vapor and liquid water sensing," IEEE Trans. Geosci. Remote Sens., vol. 45, no. 7, pp. 2202-2206, Jul. 2007.

[17] D. Cimini, E. R. Westwater, A. J. Gasiewski, M. Klein, V. Y. Leuski, and J. C. Liljegren, "Ground-based millimeter- and submillimeter-wave observations of low vapor and liquid contents," IEEE Trans. Geosci. Remote Sens., vol. 45, no. 7, pp. 2169-2180, Jul. 2007.

[18] E. R. Westwater, D. Cimini, V. Mattioli, A. Gasiewski, M. Klein, V. Leuski, and J. Liljegren, "The 2004 North Slope of Alaska Arctic winter radiometric experiment: Overview and highlights," in Proc. IEEE MicroRad, San Juan, Puerto Rico, 2006, pp. 77-81.

[19] D. Cimini, E. R. Westwater, A. J. Gasiewski, M. Klein, V. Y. Leuski, and S. Dowlatshabi, "The ground-based scanning radiometer: A powerful tool for study of the Arctic atmosphere," IEEE Trans. Geosci. Remote Sens., vol. 45 , no. 9, pp. 2759-2777, Sep. 2007.

[20] P. E. Racette, E. R. Westwater, Y. Han, A. Gasiewski, M. Klein, D. Cimini, W. Manning, E. Kim, J. Wang, and P. Kiedron, "Measurement of low amounts of precipitable water vapor using ground-based millimeterwave radiometry," J. Atmos. Ocean. Technol., vol. 22, no. 4, pp. 317-337, Apr. 2005.

[21] P. Ricaud, B. Gabard, S. Derrien, J.-P. Chaboureau, T. Rose, A. Mombauer, and H. Czekala, "HAMSTRAD-Tropo, A 183-GHz radiometer dedicated to sound tropospheric water vapor over Concordia station, Antarctica," IEEE Trans. Geosci. Remote Sens., vol. 48, no. 3, pp. 1365-1380, Mar. 2010.

[22] P. Ricaud, B. Gabard, S. Derrien, J.-L. Attié, T. Rose, and H. Czekala, "Validation of tropospheric water vapor as measured by the $183-\mathrm{GHz}$ radiometer HAMSTRAD-Tropo over the Pyrenees Mountains, France," IEEE Trans. Geosci. Remote Sens., vol. 48, no. 5, pp. 2189-2203, May 2010.

[23] F. Carminati, P. Ricaud, J.-L. Attié, C. Genthon, A. Pellegrini, J. Warner, T. August, and Y. Courcoux, "Evolution of the troposphere above Dome C, Antarctica in 2010: 1. Temperature,", 2012, manuscript in preparation, to be published.

[24] F. Carminati, P. Ricaud, J.-L. Attié, C. Genthon, A. Pellegrini, J. Warner, T. August, and Y. Courcoux, "Evolution of the troposphere above Dome C, Antarctica in 2010: 2. Water vapor,", 2012, manuscript in preparation, to be published.

[25] C. Tomasi, B. Petkov, E. Benedetti, L. Valenziano, and V. Vitale, "Analysis of a four-year radiosonde data-set at Dome $\mathrm{C}$ for characterizing temperature and moisture conditions of the Antarctic atmosphere," J. Geophys. Res., vol. 116, no. D15, pp. D15304-1-D15304-18, Aug. 2011.

[26] DigiCORA III - MW31 USER'S GUIDE, VAISALA, Helsinki, Finland, Oct. 2004, M210488EN-B.

[27] V. Mattioli, E. R. Westwater, D. Cimini, A. J. Gasiewski, M. Klein, and V. Y. Leuski, "Microwave and millimeter-wave radiometric and radiosonde observations in an Arctic environment," J. Atmos. Ocean. Technol., vol. 25, no. 10, pp. 1768-1777, Oct. 2008.

[28] A. Gettelman, V. P. Walden, L. M. Miloshevich, W. L. Roth, and B. Halter, "Relative humidity over Antarctica from radiosondes, satellites, and a general circulation model," J. Geophys. Res., vol. 111, pp. D09S13-1D09S13-13, May 2006.

[29] L. M. Miloshevich, H. Vömel, D. N. Whiteman, B. M. Lesht, F. J. Schmidlin, and F. Russo, "Absolute accuracy of water vapor measurements from six operational radiosonde types launched during AWEX-G and implications for AIRS validation," J. Geophys. Res., vol. 111, no. D9, pp. D09S10-1-D09S10-25, Apr. 2006.

[30] L. M. Miloshevich, H. Vömel, D. N. Whiteman, and T. Leblanc, "Accuracy assessment and correction of Vaisala RS92 radiosonde water vapor measurements," J. Geophys. Res., vol. 114, pp. D11305-1-D11305-23, Jun. 2009.

[31] C. Genthon, M. S. Town, D. Six, V. Favier, S. Argentini, and A. Pellegrini, "Meteorological atmospheric boundary layer measurements and ECMWF analyses during summer at Dome C, Antarctica," J. Geophys. Res., vol. 155, pp. D05104-1-D05104-15, Mar. 2010.

[32] J. A. Lerner, E. Weisz, and G. Kirchengast, "Temperature and humidity retrieval from simulated Infrared Atmospheric Sounding Interferometer (IASI) measurements," J. Geophys. Res., vol. 107, no. D14, pp. 4189-14189-11, Jul. 2002.

[33] N. Pougatchev, T. August, X. Calbet, T. Hultberg, O. Oduleye, P. Schlussel, B. Stiller, K. St. Germain, and G. Bingham, "IASI tempera- ture and water vapor retrieval-Error assessment and validation," Atmos. Chem. Phys., vol. 9, no. 17, pp. 6453-6458, Sep. 2009.

[34] IASI Level 2 Products Guide, EUMETSAT, Darmstadt, Germany, 2004, EUM/OPS-EPS/MAN/04/0033. [Online]. Available: http://oiswww. eumetsat.org/WEBOPS/eps-pg/IASI-L2/IASIL2-PG-0TOC.htm

[35] P. Schlüssel, T. H. Hultberg, P. L. Phillips, T. August, and X. Calbet, "The operational IASI Level 2 processor," Adv. Space Res., vol. 36, no. 5, pp. 982-988, 2005.

[36] F. Rabier, A. Bouchard, E. Brun, A. Doerenbecher, S. Guedj, V. Guidard, F. Karbou, V.-H. Peuch, L. El Amraoui, D. Puech, C. Genthon, G. Picard, M. Town, A. Hertzog, F. Vial, P. Cocquerez, S. A. Cohn, T. Hock, J. Fox, H. Cole, D. Parsons, J. Powers, K. Romberg, J. Vanandel, T. Deshler, J. Mercer, J. S. Haase, L. Avallone, L. Kalnajs, C. R. Mechoso, A. Tangborn, A. Pellegrini, Y. Frenot, J.-N. Thépaut, A. McNally, G. Balsamo, and P. Steinle, "The Concordiasi project in Antarctica," Bull. Amer. Meteorol. Soc., vol. 91, no. 1, pp. 69-86, Jan. 2010.

[37] J. Urban, P. Baron, N. Lautié, N. Schneider, K. Dassas, P. Ricaud, and J. De La Noë, "Moliere (v5): A versatile forward- and inversion model for the millimeter and sub-millimeter wavelength range," J. Quant. Spectrosc. Radiat. Transf., vol. 83, no. 3/4, pp. 529-554, Feb. 2004.

[38] D. Murtagh, U. Frisk, F. Merino, M. Ridal, A. Jonsson, J. Stegman, G. Witt, P. Eriksson, C. Jiménez, G. Megie, J. de la Noë, P. Ricaud, P. Baron, J. R. Pardo, A. Hauchcorne, E. J. Llewellyn, D. A. Degenstein, R. L. Gattinger, N. D. Lloyd, W. F. J. Evans, I. C. McDade, C. S. Haley, C. Sioris, C. von Savigny, B. H. Solheim, J. C. McConnell, K. Strong, E. H. Richardson, G. W. Leppelmeier, E. Kyrölä, H. Auvinen, and L. Oikarinen, "Review: An overview of the Odin atmospheric mission," Can. J. Phys., vol. 80, no. 4, pp. 309-319, Apr. 2002.

[39] E. Motte, P. Ricaud, B. Gabard, M. Niclas, and F. Gangneron, "A $22 \mathrm{GHz}$ Mobile Microwave Radiometer (MobRa) for the study of stratospheric water vapor," IEEE Trans. Geosci. Remote Sens., vol. 46, no. 10, pp. 3104-3114, Oct. 2008.

[40] N. Schneider, O. Lezeaux, J. de La Noë, J. Urban, and P. Ricaud, "Validation of ground-based observations of stratomesospheric ozone," J. Geophys. Res., vol. 108, no. D17, pp. 4540-ACH-1-4540-ACH-15, Sep. 2003.

[41] P. Ricaud, P. Baron, and J. La Noë, "Quality assessment of groundbased microwave measurements of chlorine monoxide, ozone, and nitrogen dioxide from the NDSC radiometer at the Plateau de Bure," Ann. Geophys., vol. 22, no. 6, pp. 1903-1915, Jun. 2004.

[42] H. M. Pickett, R. L. Poynter, E. A. Cohen, M. L. Delitsky, J. C. Pearson, and H. S. P. Müller, "Submillimeter, millimeter, and microwave spectral line catalog," J. Quant. Spectrosc. Radiat. Transf., vol. 60, no. 5, pp. 883890, Nov. 1998

[43] L. S. Rothman, D. Jacquemart, A. Barbe, D. Chris Benner, M. Birk, L. R. Brown, M. R. Carleer, C. Chackerian, K. Chance, L. H. Coudert, V. Dana, V. M. Devi, J.-M. Flaud, R. R. Gamache, A. Goldman, J.-M. Hartmann, K. W. Jucks, A. G. Maki, J.-Y. Mandin, S. T. Massie, J. Orphal, A. Perrin, C. P. Rinsland, M. A. H. Smith, J. Tennyson, R. N. Tolchenov, R. A. Toth, J. Vander Auwera, P. Varanasi, and G. Wagner, "The HITRAN 2004 molecular spectroscopic database," J. Quant. Spectrosc. Radiat. Transf., vol. 96, no. 2, pp. 139-204, Dec. 2005.

[44] C. D. Rodgers, Inverse Methods for Atmospheric Sounding: Theory and Practice, 1st ed. Singapore: World Scientific, 2000. 